\title{
Advanced Testing Techniques to Measure the PWSCC Resistance of Alloy 690 and its Weld Metals
}

This report describes research sponsored by EPRI and the U.S. Department of Energy under the Nuclear Energy Plant Optimization (NEPO) Program. 



\section{Advanced Testing Techniques to Measure the PWSCC Resistance of Alloy 690 and its Weld Metals}

1011202

Final Report, October 2004

Cosponsor

U.S. Department of Energy,

Nuclear Energy Plant Optimization (NEPO)

Office of Nuclear Energy, Science and Technology

1000 Independence Avenue, S.W.

Washington, DC 20585-1290

EPRI Project Managers

J. Hickling

A. Ahluwalia 


\section{DISCLAIMER OF WARRANTIES AND LIMITATION OF LIABILITIES}

THIS DOCUMENT WAS PREPARED BY THE ORGANIZATION(S) NAMED BELOW AS AN ACCOUNT OF WORK SPONSORED OR COSPONSORED BY THE ELECTRIC POWER RESEARCH INSTITUTE, INC. (EPRI). NEITHER EPRI, ANY MEMBER OF EPRI, ANY COSPONSOR, THE ORGANIZATION(S) BELOW, NOR ANY PERSON ACTING ON BEHALF OF ANY OF THEM:

(A) MAKES ANY WARRANTY OR REPRESENTATION WHATSOEVER, EXPRESS OR IMPLIED, (I) WITH RESPECT TO THE USE OF ANY INFORMATION, APPARATUS, METHOD, PROCESS, OR SIMILAR ITEM DISCLOSED IN THIS DOCUMENT, INCLUDING MERCHANTABILITY AND FITNESS FOR A PARTICULAR PURPOSE, OR (II) THAT SUCH USE DOES NOT INFRINGE ON OR INTERFERE WITH PRIVATELY OWNED RIGHTS, INCLUDING ANY PARTY'S INTELLECTUAL PROPERTY, OR (III) THAT THIS DOCUMENT IS SUITABLE TO ANY PARTICULAR USER'S CIRCUMSTANCE; OR

(B) ASSUMES RESPONSIBILITY FOR ANY DAMAGES OR OTHER LIABILITY WHATSOEVER (INCLUDING ANY CONSEQUENTIAL DAMAGES, EVEN IF EPRI OR ANY EPRI REPRESENTATIVE HAS BEEN ADVISED OF THE POSSIBILITY OF SUCH DAMAGES) RESULTING FROM YOUR SELECTION OR USE OF THIS DOCUMENT OR ANY INFORMATION, APPARATUS, METHOD, PROCESS, OR SIMILAR ITEM DISCLOSED IN THIS DOCUMENT.

ORGANIZATION(S) THAT PREPARED THIS DOCUMENT

General Electric Global Research Center

\section{ORDERING INFORMATION}

Requests for copies of this report should be directed to EPRI Orders and Conferences, 1355 Willow Way, Suite 278, Concord, CA 94520, (800) 313-3774, press 2 or internally x5379, (925) 609-9169, (925) 609-1310 (fax).

Electric Power Research Institute and EPRI are registered service marks of the Electric Power Research Institute, Inc. EPRI. ELECTRIFY THE WORLD is a service mark of the Electric Power Research Institute, Inc.

Copyright $\odot 2004$ Electric Power Research Institute, Inc. All rights reserved. 


\section{CITATIONS}

This report was prepared by

General Electric Global Research Center

P.O. Box 8, K103A39

Schenectady, NY 12301

Principal Investigator

P. Andresen

This document describes research sponsored by EPRI and U.S. Department of Energy under the Nuclear Energy Plant Optimization (NEPO) Program, NEPO Task FY02-3-207.

The report is a corporate document that should be cited in the literature in the following manner:

Advanced Testing Techniques to Measure the PWSCC Resistance of Alloy 690 and its Weld

Metals, EPRI, Palo Alto, CA, and U.S. Department of Energy, Washington, DC: 2004. 1011202. 



\section{REPORT SUMMARY}

Wrought Alloy 600 and its weld metals (Alloy 182 and Alloy 82) were originally used in pressurized water reactors (PWRs) due to the material's inherent resistance to general corrosion in a number of aggressive environments and because of a coefficient of thermal expansion that is very close to that of low alloy and carbon steel. Over the last thirty years, stress corrosion cracking in PWR primary water (PWSCC) has been observed in numerous Alloy 600 component items and associated welds, sometimes after relatively long incubation times. The occurrence of PWSCC has been responsible for significant downtime and replacement power costs.

Component repairs and replacements have generally utilized wrought Alloy 690 material and its compatible weld metals (Alloy 152 and Alloy 52), which have been shown to be highly resistant to PWSCC in most laboratory experiments and have been free from cracking in operating reactors over periods already up to nearly 15 years. The remaining challenge, however, is to quantify the longevity of these materials with respect to PWSCC in order to provide a sound technical basis for the development of future inspection requirements for repaired or replaced component items.

\section{Approach}

The task at hand seeks ways of demonstrating the satisfactory long-term performance of Alloys 690/52/152 in primary water which go beyond presumed "immunity" to cracking and permit the quantification of factors of improvement in crack growth rate (CGR) with regard to Alloy 600 and its weld metals for these more resistant materials. In this initial "proof of concept" demonstration, several moderate accelerants were used, but the main focus was on very sensitive crack growth measurement techniques and improved testing protocols.

\section{Results \& Findings}

The goal of this limited program - to develop advanced techniques to evaluate the PWSCC resistance of Alloy 690 - was successfully achieved. As has been consistently shown for many other SCC-resistant materials, some inherent susceptibility to SCC was still observed to exist. Thus, while Alloy 690 lived up to its good reputation as an SCC-resistant material, stable, sustained SCC growth - albeit at very low rates - was observed on two cold-worked specimens during the entire 2400 hour test duration at constant stress intensity in simulated primary water at $340{ }^{\circ} \mathrm{C}$. The crack morphology at truly constant load was primarily transgranular, although some evidence of intergranular primary and secondary cracking was observed. Since grain boundaries are almost always the weak point in the microstructure, the observation of transgranular cracking is consistent with a material that possesses inherently high resistance to SCC.

\section{Applications, Values \& Use}

As part of an ongoing, comprehensive program involving utilities, reactor vendors and engineering/research organizations, this report will help to ensure that corrosion degradation of 
nickel-base alloys does not limit service life and that full benefit can be obtained from improved designs for both replacement components and new reactors.

\section{EPRI Perspective}

The main challenge facing the project team was to adapt to the task at hand the very sensitive crack growth measurement techniques and improved testing protocols developed over 30 years at GE Research to optimize the evaluation of SCC susceptibility in general, and the quantification of benefits associated with mitigation or new materials in particular. Because plant components are designed for long lives, even the most sensitive crack following techniques would require very long test times (years) for characterization under fully representative plant conditions. Thus, some types of moderate acceleration are appropriate, but these have to be chosen with great care to avoid obtaining misleading results.

With the success of this "proof-of-concept" study, it is anticipated that additional testing will be performed to quantify the behavior of both wrought alloys and weld metals as a function of key variables such as material composition and processing.

\section{Keywords}

Alloy 600, Alloy 690, PWSCC, Material Degradation, Predictive Maintenance. 


\section{ABSTRACT}

Stress corrosion cracking (SCC) of most iron- and nickel-base structural materials has occurred in LWR environments. Variations in the processing and composition of these materials have improved their resistance to SCC in general and primary water SCC (PWSCC) in particular, but many decades of laboratory data and field experience have cast doubt on the concept of immunity to SCC. One reason for this is that the types of laboratory testing chosen, and their implementation, have not usually been optimally sensitive to accurately discern the material's long-term resistance to SCC in realistic operating environments.

The task at hand seeks ways of demonstrating the satisfactory long-term performance of Alloys 690/52/152 in primary water which go beyond presumed "immunity" to cracking and permit the quantification of factors of improvement in crack growth rate (CGR) with regard to Alloy 600 and its weld metals for these more resistant materials. In this initial "proof of concept" demonstration, several moderate accelerants were used, but the main focus was on very sensitive crack growth measurement techniques and improved testing protocols.

The goal of this limited program - to develop advanced techniques to evaluate the PWSCC resistance of Alloy 690 - was successfully achieved. As has been consistently shown for many other SCC-resistant materials, some inherent susceptibility to SCC was still observed to exist. Thus, while Alloy 690 lived up to its good reputation as an SCC-resistant material, stable, sustained SCC growth - albeit at very low rates - was observed on two cold-worked specimens during the entire 2400 hour test duration at constant stress intensity in simulated primary water at $340^{\circ} \mathrm{C}$. The crack morphology at truly constant load was primarily transgranular, although some evidence of intergranular primary and secondary cracking was observed. Since grain boundaries are almost always the weak point in the microstructure, the observation of transgranular cracking is consistent with a material that possesses inherently high resistance to SCC. 



\section{CONTENTS}

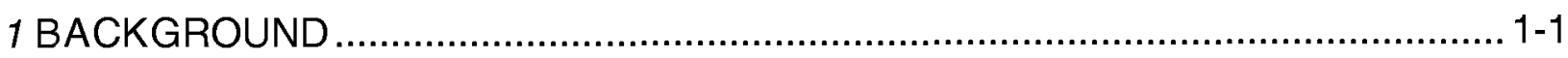

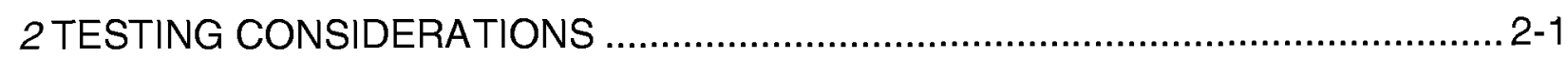

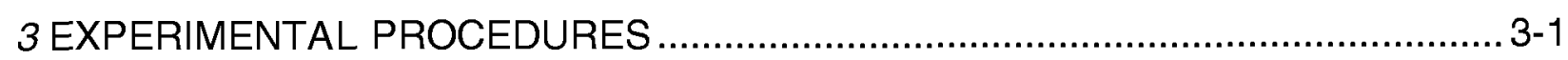

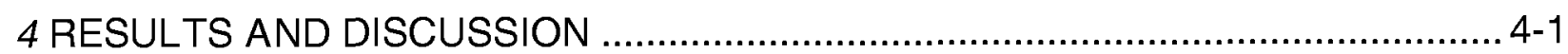

Specimen c248, Alloy $690,1800^{\circ} \mathrm{F}$ Anneal .......................................................... 4-1

Specimen c249, Alloy 690, 2000F Anneal ...................................................... 4-8

Comparison and Interpretation of Crack Growth Rate Data................................ 4-16

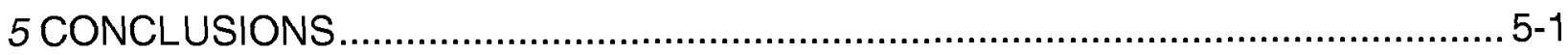

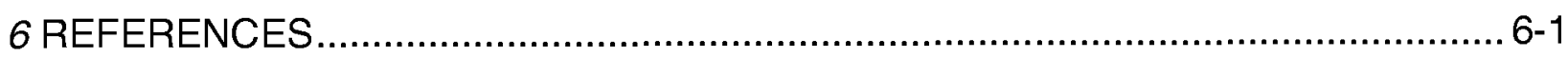





\section{LIST OF FIGURES}

Figure 2-1 Residual Strain from Weld Shrinkage Strain in the Heat Affected Zone of Stainless Steels as Measured by a Novel Electron Back-Scattered Technique. Deformation is Expressed in Terms of Equivalent Tensile Strain at Room Temperature, and Results from Shrinkage Strains During Welding [11-13]

Figure 2-2 $\mathrm{Ni}$ and $\mathrm{NiO}$ Phase Stability as a Function of Temperature and $\mathrm{H} 2$ Fugacity. Newer, More Precise Measurements at KAPL are Represented by the Lower Dashed Line [14-16].

Figure 3-1 Schematic of the Reversing dc Potential Drop System used for High Resolution Crack Monitoring [6, 7]

Figure 3-2 Example of Crack Length Resolution in Nickel Alloy 182 Weld Metal Tested in $288^{\circ} \mathrm{C}$ Water Containing $95 \mathrm{ppb} \mathrm{H}_{2}$ showing the Ability to Resolve Crack Growth Rates in the Mid-10-9 mm/s Range. [3, 6, 7]

Figure 4-1 Overview of the Crack Length vs. Time Response of Specimen c248 of Alloy 690 , Heat NX8244HK111 given an $1800^{\circ} \mathrm{F}$ Anneal then Forged to $25 \%$ Reduction in Thickness at $25^{\circ} \mathrm{C}$

Figure 4-2 Crack Length vs. Time Response During Air Fatigue Precracking of Specimen c248 of Alloy 690, Heat NX8244HK111 given an $1800^{\circ} \mathrm{F}$ Anneal then Forged to $25 \%$ Reduction in Thickness at $25^{\circ} \mathrm{C}$

Figure 4-3 Crack Length vs. Time Response of Specimen c248 of Alloy 690, Heat NX8244HK111 given an $1800^{\circ} \mathrm{F}$ anneal then Forged to $25 \%$ Reduction in Thickness at $25^{\circ} \mathrm{C}$

Figure 4-4 Crack Length vs. Time Response of Specimen c248 of Alloy 690, Heat NX8244HK111 given an $1800^{\circ} \mathrm{F}$ Anneal then Forged to $25 \%$ Reduction in Thickness at $25^{\circ} \mathrm{C}$

Figure 4-5 Macrograph of 0.5TCT Specimen c248 of Alloy 690, Heat NX8244HK111 given an $1800^{\circ} \mathrm{F}$ Anneal then Forged to $25 \%$ Reduction in Thickness at $25^{\circ} \mathrm{C}$

Figure 4-6 Macrograph of Cross-Sectional Metallography of 0.5TCT Specimen c248 of Alloy 690 , Heat NX8244HK111, given a $1800^{\circ} \mathrm{F}$ Anneal then Forged to $25 \%$ Reduction in Thickness at $25^{\circ} \mathrm{C}$. The Machined Notch Angles up at the Upper Right, and this View Encompasses the Region of Air Fatigue Precracking and $340^{\circ} \mathrm{C}$ SCC. Significant Compositional Banding is Present, as Primarily Evidenced by the Vertical "Stripes" Comprised of Regions of High Carbide Density. There is a Range of Grain Sizes (Smaller on Average than for the $2000^{\circ} \mathrm{F}$ Anneal), and a Lower Level of Grain Boundary Carbides

Figure 4-7 Micrograph of Cross-Sectional Metallography of 0.5TCT Specimen c248 of

Alloy 690 , Heat NX8244HK111, given an $1800^{\circ} \mathrm{F}$ Anneal then Forged to $25 \%$ Reduction in Thickness at $25^{\circ} \mathrm{C}$. This is a Higher Magnification View Near the End of the $340^{\circ} \mathrm{C} \mathrm{SCC} \mathrm{Crack,} \mathrm{which} \mathrm{also} \mathrm{shows} \mathrm{the} \mathrm{Compositional} \mathrm{Banding} \mathrm{and} \mathrm{Non-}$ Uniform Carbide Distribution 
Figure 4-8 Scanning Electron Micrograph of 0.5TCT Specimen c248 of Alloy 690, Heat NX8244HK111 given an $1800^{\circ} \mathrm{F}$ Anneal then Forged to $25 \%$ Reduction in

Thickness at $25^{\circ} \mathrm{C}$

Figure 4-9 Scanning Electron Micrograph of 0.5TCT Specimen c248 of Alloy 690, Heat NX8244HK111 given an $1800^{\circ} \mathrm{F}$ Anneal then Forged to $25 \%$ Reduction in Thickness at $25^{\circ} \mathrm{C}$

Figure 4-10 Scanning Electron Micrograph of 0.5TCT Specimen c248 of Alloy 690, Heat NX8244HK111 given an $1800^{\circ} \mathrm{F}$ Anneal then Forged to $25 \%$ Reduction in Thickness at $25^{\circ} \mathrm{C}$

Figure 4-11 Scanning Electron Micrograph of 0.5TCT Specimen c248 of Alloy 690, Heat NX8244HK111 given an $1800^{\circ} \mathrm{F}$ Anneal then Forged to $25 \%$ Reduction in Thickness at $25^{\circ} \mathrm{C}$

Figure 4-12 Scanning Electron Micrograph of 0.5TCT Specimen c248 of Alloy 690, Heat $\mathrm{NX} 8244 \mathrm{HK} 111$ given an $1800^{\circ} \mathrm{F}$ Anneal then Forged to $25 \%$ Reduction in Thickness at $25^{\circ} \mathrm{C}$

Figure 4-13 Overview of the Crack Length vs. Time Response of Specimen c249 of Alloy 690 , Heat NX8244HK112 given an $2000^{\circ} \mathrm{F}$ Anneal then Forged to $20 \%$ Reduction in Thickness at $25^{\circ} \mathrm{C}$

Figure 4-14 Crack Length vs. Time Response During Air Fatigue Precracking of Specimen c249 of Alloy 690, Heat NX8244HK112 given an $2000^{\circ} \mathrm{F}$ Anneal then Forged to $20 \%$ Reduction in Thickness at $25^{\circ} \mathrm{C}$

Figure 4-15 Crack Length vs. Time Response of Specimen c249 of Alloy 690, Heat NX8244HK112 given an $2000^{\circ} \mathrm{F}$ Anneal then Forged to $20 \%$ Reduction in Thickness at $25^{\circ} \mathrm{C}$

Figure 4-16 Crack Length vs. Time Response of Specimen c249 of Alloy 690, Heat NX8244HK112 given an $2000^{\circ} \mathrm{F}$ Anneal then Forged to $20 \%$ Reduction in Thickness at $25^{\circ} \mathrm{C}$

Figure 4-17 Macrograph of 0.5TCT Specimen c249 of Alloy 690, Heat NX8244HK111, given a $2000^{\circ} \mathrm{F}$ Anneal then Forged to $20 \%$ Reduction in Thickness at $25^{\circ} \mathrm{C}$

Figure 4-18 Macrograph of Cross-Sectional Metallography of 0.5TCT Specimen c249 of Alloy 690 , Heat NX8244HK111, given a $2000^{\circ} \mathrm{F}$ Anneal then Forged to $20 \%$ Reduction in Thickness at $25^{\circ} \mathrm{C}$. The Machined Notch Angles up at the Upper Right, and this View Encompasses the Region of Air Fatigue Precracking and $340^{\circ} \mathrm{C}$ SCC. Compositional Banding is Dramatically Less than in c248 $\left(1800^{\circ} \mathrm{F}\right.$ Anneal). The Grain Sizes is also more Uniform, and the Density of Grain Boundary Carbides is Higher.

Figure 4-19 Micrograph of Cross-Sectional Metallography of 0.5TCT Specimen c249 of Alloy 690 , Heat NX8244HK111, given a $2000^{\circ} \mathrm{F}$ Anneal then Forged to $20 \%$ Reduction in Thickness at $25^{\circ} \mathrm{C}$. This is a Higher Magnification View Near the End of the $340^{\circ} \mathrm{C}$ SCC Crack

Figure 4-20 Scanning Electron Micrograph of 0.5TCT Specimen c249 of Alloy 690, Heat NX8244HK111, given a $2000^{\circ} \mathrm{F}$ Anneal then Forged to $20 \%$ Reduction in Thickness at $25^{\circ} \mathrm{C}$

Figure 4-21 Scanning Electron Micrograph of 0.5TCT Specimen c249 of Alloy 690, Heat NX8244HK111, given a $2000^{\circ} \mathrm{F}$ Anneal then Forged to $20 \%$ Reduction in Thickness at $25^{\circ} \mathrm{C}$ 
Figure 4-22 Scanning Electron Micrograph of 0.5TCT Specimen c249 of Alloy 690, Heat NX8244HK111, given a $2000^{\circ} \mathrm{F}$ Anneal then Forged to $20 \%$ Reduction in Thickness at $25^{\circ} \mathrm{C}$

Figure 4-23 Scanning Electron Micrograph of 0.5TCT Specimen c249 of Alloy 690, Heat $\mathrm{NX} 8244 \mathrm{HK} 111$, given a $2000^{\circ} \mathrm{F}$ Anneal then Forged to $20 \%$ Reduction in Thickness at $25^{\circ} \mathrm{C}$

Figure 4-24 Scanning Electron Micrograph of 0.5TCT Specimen c249 of Alloy 690, Heat NX8244HK111, given a $2000^{\circ} \mathrm{F}$ Anneal then Forged to $20 \%$ Reduction in Thickness at $25^{\circ} \mathrm{C}$

Figure 4-25 Pourbaix ( $\mathrm{pH}$ - Potential) Diagram for the $\mathrm{Ni}-\mathrm{H}_{2} \mathrm{O}$ system at $300^{\circ} \mathrm{C}$ showing that the $\mathrm{H}_{2} / \mathrm{H}_{2} \mathrm{O}$ Line (which Controls the Corrosion Potential) is Parallel to the $\mathrm{Ni} / \mathrm{NiO}$ Boundary

Figure 4-26 Crack Length vs. Time Response of Specimen c261 of Alloy 690, Heat 93510 (CRDM Housing) Tested in $325^{\circ} \mathrm{C}$ PWR Water with $20 \mathrm{cc} / \mathrm{kg} \mathrm{H} 2$ showing the Absence of an Effect on Crack Growth Rate of a $0.3 \mathrm{pH}$ Unit Change in B/Li Chemistry ..... 



\section{LIST OF TABLES}

Table 3-1 Composition and Properties of Alloy 690 Plate EPRI Heat NX8244HK11 used

in Two Heat Treatment Conditions: 1800F (1A) \& 2000F (1B) Anneal ............................. 3-1

Table 4-1 Crack Growth Rates Measured during Fatigue Pre-Cracking and SCC Testing .....4-16 



\section{1 \\ BACKGROUND}

Stress corrosion cracking (SCC) of most iron- and nickel-base structural materials has occurred in light water reactor environments [1-5]. Variations in the processing and composition of these materials have improved their resistance to SCC in general and primary water SCC (PWSCC) in particular, but many decades of laboratory data and field experience have cast doubt on the concept of immunity to SCC. Combinations of materials, environments, and stressing conditions - such as unsensitized stainless steel in BWR or PWR water at a stress intensity of up to perhaps $25 \mathrm{MPa} \sqrt{\mathrm{m}}$ - once generally viewed as very resistant to SCC have now been shown to have low to moderate susceptibility $[1,2,5-7]$. One reason for this is that the types of laboratory testing chosen, and their implementation, have not usually been optimally sensitive to accurately discern the material's long-term resistance to SCC in realistic operating environments.

Historically, most stress corrosion cracking (SCC) tests have relied on accelerated techniques to measure SCC susceptibility. Common examples include slow strain rate (SSR) testing, creviced bent beams (CBB) and U-bends, and reverse U-bends (RUBs). SSR tests impose dynamic strain and thereby can accelerate environmentally assisted cracking. Since they impose a fixed test time limit (associated, in the absence of SCC, with ductile overload) they may not always provide sufficient time/opportunity for crack initiation. Furthermore, the applied loads plastically "yaw" the crack open, thereby potentially producing mechanical blunting and a different crack tip environment than can develop in a sharp crack. For these and other reasons, SSR tests may, in fact, not always accelerate SCC, but can even inhibit it, or otherwise give a misleading impression of susceptibility. In addition, the results are difficult to relate to the type of loading experienced by most LWR components.

Constant displacement specimens (bent beams, U-bends, etc.) share some similar drawbacks. Stresses and strains are generally unrealistically high, and the specimens can be very sensitive to surface oxides, surface finish, surface preparation, etc. All constant displacement specimens suffer from load loss upon heating the autoclave as the modulus of the material changes vs. temperature. Also, there are some instances, esp. in Alloy 600, where much greater stress relaxation (e.g., $\geq 75 \%$ ) occurs during the test from thermal creep, rendering the results almost meaningless in terms of demonstrating apparent resistance to SCC.

The optimal test is always one that closely simulates the actual service, including overall time of exposure, but this is intractable for systems designed for 40 year lifetimes. An additional criterion is the ability to provide good test-to-test reproducibility, high statistical confidence, and very sensitive detection of crack development. Tests designed to evaluate crack initiation suffer in almost all of these categories - the degree to which they are representative is uncertain because of: sensitivity to surface condition; the reproducibility is often poor; the statistical design of the tests may be marginal if an adequate number of specimens and continuous monitoring of the time to cracking is not employed; and the sensitivity to crack development is often low 
(e.g., only severe cracking or failure is detected). Indeed, many initiation tests are performed using a handful of specimens and test interruption at 1000 - 3000 hour intervals; under such conditions the statistical confidence in the result is always low. Without representative conditions and sensitive test techniques, it can be difficult or impossible to know the extent of problems with existing materials, or the adequacy of the benefit of SCC countermeasures and the true behavior of new materials. 


\section{TESTING CONSIDERATIONS}

For 30 years, GE Research has focused on very sensitive crack growth measurement techniques (esp. reversing dc potential drop) and improved testing protocols (e.g., transitioning from transgranular precracking to intergranular SCC) to optimize the approach to evaluating SCC susceptibility in general, and quantifying benefits associated with mitigation or new materials in particular. It is widely acknowledged that beyond some arbitrarily small dimension, crack development is controlled by crack advance, and this typically occupies a large fraction of structural component lifetime. Even in cases where this is not so apparent, there are strong reasons to believe that many of the same processes and dependencies that characterize and control the earliest stages of incipient cracking also apply to crack growth. Importantly, crack growth can be viewed as quantifying the inherent resistance of the material to SCC, since a large volume of material is sampled in crack growth tests in contrast to the local surface anomalies and inhomogeneities that can bias initiation test results.

Because plant components are designed for long lives, even the most sensitive crack following techniques would require very long test times (years) for characterization under fully representative plant conditions. Thus, some types of moderate acceleration are appropriate. The task at hand seeks ways of demonstrating the satisfactory long-term performance of Alloys 690/52/152 in primary water which go beyond presumed "immunity" to cracking and permit the quantification of factors of improvement in crack growth rate (CGR) with regard to Alloy 600 and its weld metals for these more resistant materials. In this initial demonstration program, several moderate accelerants were used:

- First, because residual strain is inevitable in weld heat affected zones (Figure 2-1) and residual deformation is common in most fabricated components, the tests used alloys that had been strained by $\approx 20 \%$.

- Second, while some plant component cracks never achieve high stress intensity factors, the SCC response was quantified at $\sim 25 \mathrm{ksi} V$ in, a realistic value that can be achieved while meeting linear elastic fracture mechanics criteria.

- Third, very gentle cyclic loading was used prior to establishing constant stress intensity factor conditions to help ensure that well-behaved, meaningful data were obtained.

- Fourth, a somewhat elevated temperature of $340^{\circ} \mathrm{C}$ was used, although one that is achieved in the pressurizer of PWRs.

- Finally, while not an accelerant per se, testing was carried out under $\mathrm{H} 2$ fugacity/temperature conditions $\left(340^{\circ} \mathrm{C}\right.$ and $\left.18 \mathrm{cc} / \mathrm{kg} \mathrm{H} 2\right)$ that are close to the Ni/NiO transition (Figure 2-2), which is known to lead to more rapid cracking in Alloy 600 [14-16].

These accelerating factors can be adjusted for future work, but in a short term, limited scope demonstration program we believed this to be a wise approach. 

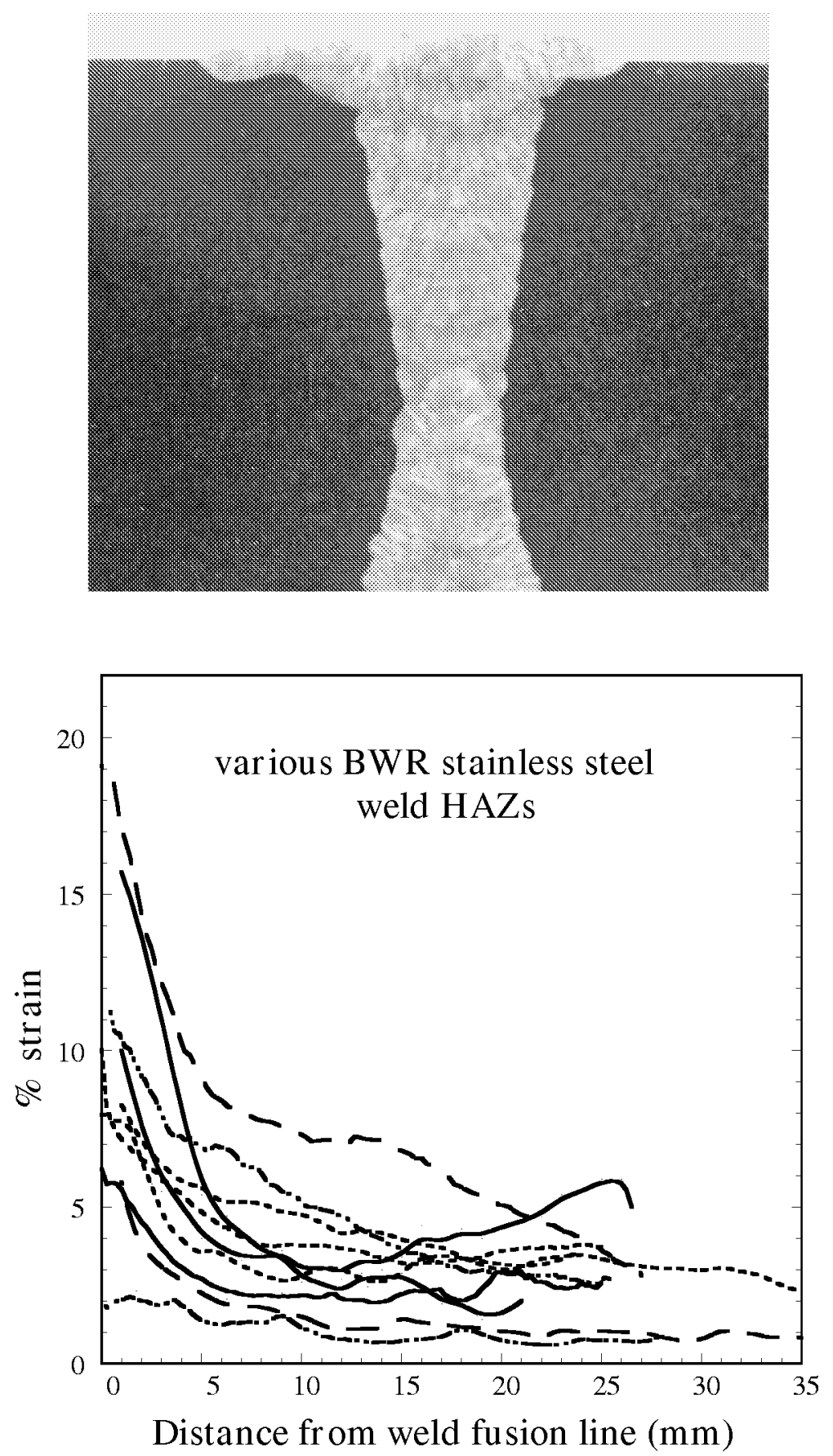

Figure 2-1

Residual Strain from Weld Shrinkage Strain in the Heat Affected Zone of Stainless Steels as Measured by a Novel Electron Back-Scattered Technique. Deformation is Expressed in Terms of Equivalent Tensile Strain at Room Temperature, and Results from Shrinkage Strains During Welding [11-13] 


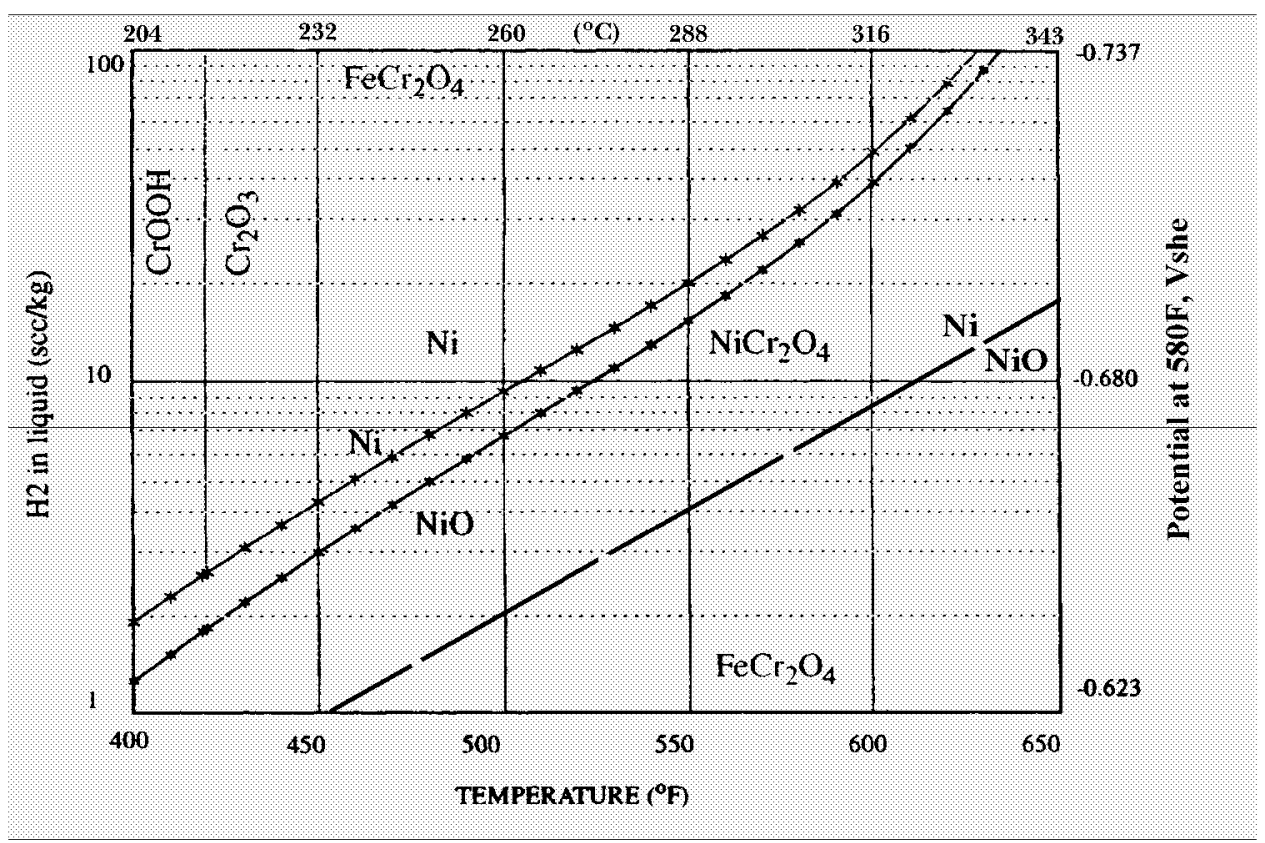

Figure 2-2

$\mathrm{Ni}$ and NiO Phase Stability as a Function of Temperature and $\mathrm{H} 2$ Fugacity. Newer, More Precise Measurements at KAPL are Represented by the Lower Dashed Line [14-16] 



\section{EXPERIMENTAL PROCEDURES}

Alloy 690 in plate form was provided by A. McIlree of EPRI, and was received from the EPRI NDE Center. The composition and mechanical properties are shown in Table 3-1. One plate had received a final anneal at $1800^{\circ} \mathrm{F}$, and one at $2000^{\circ} \mathrm{F}$. Pieces were cut at GE Research, and cold work was introduced by forging at room temperature. The procedure was optimized so as to achieve as uniform a degree of cold work as possible. Compact tension type (0.5T CT) specimens were machined with $5 \%$ side grooves on each side. Because two specimens were to be tested in tandem, the specimens were first individually fatigue precracked in air under similar conditions to an identical crack depth.

Table 3-1

Composition and Properties of Alloy 690 Plate EPRI Heat NX8244HK11 used in Two Heat Treatment Conditions: 1800F (1A) \& 2000F (1B) Anneal

\begin{tabular}{|c|c|c|c|c|c|c|c|c|c|}
\hline $\mathbf{C r}$ & $\mathbf{F e}$ & $\mathbf{A l}$ & $\mathbf{T i}$ & $\mathbf{M n}$ & $\mathbf{S i}$ & $\mathbf{C}$ & $\mathbf{S}$ & $\mathbf{P}$ & $\mathbf{N}$ \\
\hline 30.03 & 9.20 & 0.36 & 0.20 & 0.20 & 0.14 & 0.018 & $<.001$ & 0.004 & 0.01 \\
\hline
\end{tabular}

\begin{tabular}{|c|c|c|c|c|c|}
\hline Piece No. & $\begin{array}{c}\text { HR*/Annealing } \\
\text { Temp. }\end{array}$ & R.T. Yield & R.T. UTS & $\% \boldsymbol{\varepsilon}$ & $\mathbf{R b}$ \\
\hline 1A & $1800 \mathrm{~F}$ & $35.1 \mathrm{ksi}$ & $95.2 \mathrm{ksi}$ & 51.0 & 78 \\
\hline 1B & $2000 \mathrm{~F}$ & $30.4 \mathrm{ksi}$ & $86.3 \mathrm{ksi}$ & 59.0 & 70 \\
\hline
\end{tabular}

"Hot rolled from 4" thickness to 1" thick plate in 3 successive 1" rolling steps, each followed by reheating Final anneal performed for $1 \mathrm{hr}$., A.C. at the same temperature as hot rolling.

The CT specimens were instrumented with platinum current and potential probe leads for dc potential drop crack length measurements of crack length (Figures 3-1 and 3-2). In this technique, current flow through the sample is reversed about once per second primarily to reduce measurement errors associated with thermocouple effects and amplifier offsets. The computer control of current reversal, data acquisition, data averaging techniques, the relationship between measured potential and crack length, and control of constant stress intensity factor have been presented previously [2, 3, 6-9]. Data were stored in a permanent disk file typically once every 1.5 hours. In addition to the data record number, total elapsed and incremental time, and crack length, the system measured and stored temperature, current, corrosion potential, dissolved gases, influent and effluent conductivity, load and time/date. Additionally, both operator and automated program messages describing changes in test conditions and test status were a permanent part of the data record. 
Schematic of dc Potential Drop System

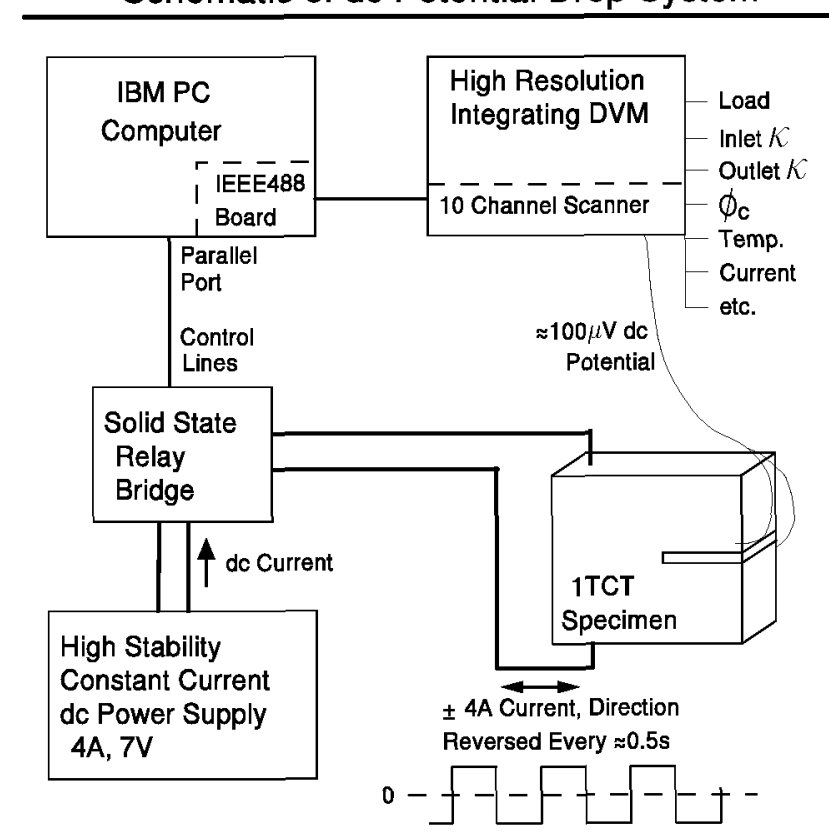

Figure 3-1

Schematic of the Reversing dc Potential Drop System used for High Resolution Crack Monitoring $[6,7]$

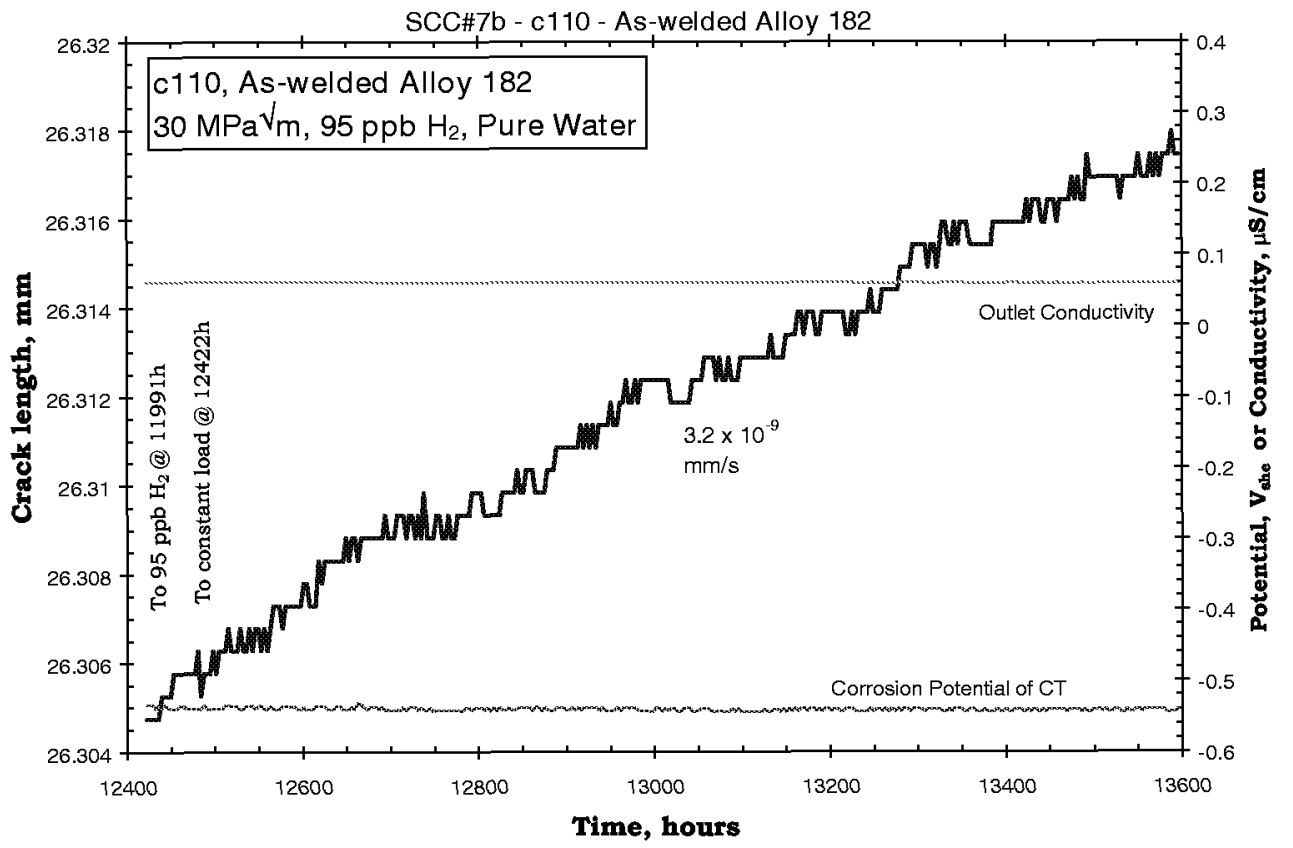

Figure 3-2

Example of Crack Length Resolution in Nickel Alloy 182 Weld Metal Tested in $288^{\circ} \mathrm{C}$ Water Containing 95 ppb $\mathrm{H}_{2}$ showing the Ability to Resolve Crack Growth Rates in the Mid-10-9 mm/s Range. [3, 6, 7] 
The CT specimens were electrically insulated from the loading pins using zirconia sleeves, and within the autoclave a zirconia washer also isolated the upper pull rod from the internal load frame. The lower pull rod was electrically isolated from the autoclave using an Omniseal pressure seal and from the loading actuator using an insulating washer. Ground isolated instrumentation was used for the platinum current and potential probe attachments to the specimen. In contrast to recommendations for nickel alloy (esp. Alloy 600) testing [17-20], no separate resistivity coupon was used because the extent of the change in electrical resistivity is limited in alloy 690, and is also completed more rapidly in cold worked materials.

Fatigue crack extension from the machined notch by 0.5 to $2.0 \mathrm{~mm}$ was generally performed at $1 \mathrm{~Hz}$ at a load ratio $(\mathrm{Kmin} / \mathrm{Kmax}) \mathrm{R}=0.3,0.5$ and 0.7 and at a Kmax somewhat below the test value of about $27.5 \mathrm{MPa} \sqrt{\mathrm{m}}$. Subsequent precracking in the environment to transition the crack morphology and plastic zone characteristics was performed by decreasing frequency to $0.001 \mathrm{~Hz}$, then by introducing a hold time at Kmax (while maintaining $\mathrm{R}=0.7$ ), and finally by switching to fully static load. Testing was performed using an Interactive Instruments Models servo-controlled systems equipped with digital controls that provide improved machine control and full computer interface/control capabilities, including constant $\mathrm{K}$ control, $\mathrm{K}$ rising/falling profiles, and multi-condition tables that permit different $\mathrm{K} / \mathrm{R} /$ frequency/hold time conditions to be sequentially evaluated. Constant $\mathrm{K}$ control was employed in most tests, with load corrections applied after very small increases in stress intensity, typically $<0.1 \%$. To avoid "hunting" (increases and decreases in load), apparent decreases in crack length never led to load corrections. Crack growth rates can be considered statistically meaningful when the crack growth increment is at least 10 times the resolution of the technique, which is typically 1 to $5 \mu \mathrm{m}$ (Figure $3-2$ ).

Deaerated, demineralized water was used to mix the initial chemistry of $1500 \mathrm{ppm} \mathrm{B}$ (as $\mathrm{H}_{3} \mathrm{BO}_{3}$ ) and $2 \mathrm{ppm} \mathrm{Li} \mathrm{(as} \mathrm{LiOH}$ ). To maintain a low-impurity environment throughout the test, a moderately high flow rate was used $(100-150 \mathrm{cc} / \mathrm{min}$, which corresponds to a refresh rate of about one autoclave volume exchange every $20-25$ minutes. Water was recirculated, with purity ensured using a mixed bed demineralizer that had been equilibrated at the $\mathrm{B}$ and $\mathrm{Li}$ concentration of interest. Because Li is released from the demineralizer as (mostly metal) cations are absorbed, some adjustment to the chemistry was necessary during the test.

$\mathrm{H}_{2}$ was continuously bubbled at the appropriate pressure through a narrow, tall glass column (6.4-cm diameter by $183 \mathrm{~cm}$ long). A low pressure pump provided positive pressure to the high pressure pump, and drew water from and recirculated excess water (water that did not go into the high pressure pump) back into the glass column. The autoclave effluent was back-pressure regulated, then measured for conductivity using a Sybron Barnstead Model PM-512. Tests were performed in 4 liter stainless steel autoclaves at $340^{\circ} \mathrm{C}$ and $17.2 \mathrm{MPa}(2500 \mathrm{psi})$. 
Corrosion potentials of the CT specimen and a Pt coupon were measured using a zirconia membrane reference electrode [10], whose reference potential in water at $340^{\circ} \mathrm{C}$ with a $\mathrm{pH} 340^{\circ} \mathrm{C}$ of 7.60 is $-595 \mathrm{mV}$ she. A fixed conversion factor was used throughout the test, even though some change in chemistry occurred. As cation impurities are absorbed, the primary species released by the deminerlizer is $\mathrm{Li}+$, and by the end of the test the chemistry had changed from $550 \mathrm{ppm} \mathrm{B}$ and $1.1 \mathrm{ppm} \mathrm{Li}$ to $535 \mathrm{ppm} \mathrm{B}$ and $2.5 \mathrm{ppm} \mathrm{Li}$, which changes the $\mathrm{pH}$ at $340^{\circ} \mathrm{C}$ from 7.60 to 7.95 . This, in turn, produces a decrease in the actual potential of $42.6 \mathrm{mV}(121.7 \mathrm{mV} / \mathrm{pH}$ $\mathrm{x} 0.35 \mathrm{pH}$ unit change). However, note that the $\mathrm{ZrO}_{2}$ electrode reference potential and the specimen and $\mathrm{Pt}$ corrosion potential have the same dependence on $\mathrm{pH}$, so the measured corrosion potential appears constant, even though it is decreasing somewhat throughout the test by 42.6 $\mathrm{mV}$, roughly in proportion to the change in solution conductivity. 


\section{RESULTS AND DISCUSSION}

The successful observation of SCC growth at constant stress intensity factor in materials of low to moderate susceptibility is often dependent on a very smooth and complete transition from the transgranular fatigue precracking conditions to conditions appropriate to SCC growth. The purpose of this program was to determine whether such highly sensitive techniques could achieve stable, sustained growth in two specimens of cold worked alloy 690.

\section{Specimen c248, Alloy $690,1800^{\circ} \mathrm{F}$ Anneal}

The first specimen, c248, was fabricated from the alloy 690 with the $1800^{\circ} \mathrm{F}$ anneal. For alloy 600 , such lower temperature anneals generally lead to higher susceptibility, but it's not clear whether this applies to alloy 690. The overview of the test is shown in Figure 4-1. The air fatigue precracking was performed at a variety of $\mathrm{Kmax}$ and $\Delta \mathrm{K}$ conditions, as shown in Figure 4-2. The purpose is to initiate the crack from the machined notch, then shift toward the Kmax to be used in the SCC test while also increasing the load ratio, $\mathrm{R}$, thereby also approaching a $\Delta \mathrm{K}$ of zero (constant K). Figure 4-2 shows the typical crisp transitions in growth rate as the loading changes are made. All testing was performed under constant $\mathrm{K}$ conditions, so load shedding occurred as the crack grew.

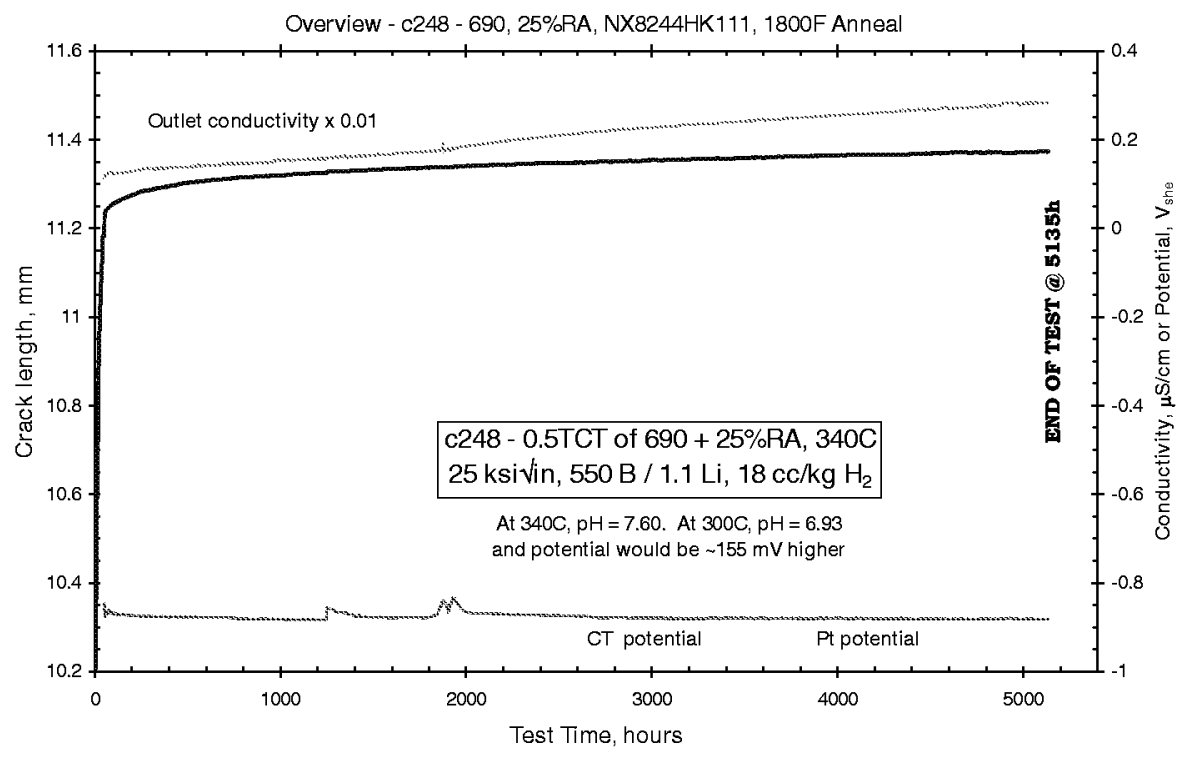

Figure 4-1

Overview of the Crack Length vs. Time Response of Specimen c248 of Alloy 690, Heat NX8244HK111 given an $1800^{\circ} \mathrm{F}$ Anneal then Forged to $25 \%$ Reduction in Thickness at $25^{\circ} \mathrm{C}$ 
The specimen was then assembled into the autoclave with specimen c249, and the autoclave filled with $\mathrm{H} 2$-deaerated water containing $550 \mathrm{ppm} \mathrm{B}$ and $1.1 \mathrm{ppm} \mathrm{Li}$ and heated. The system was allowed to equilibrate for a few days, then the specimens were loaded at a Kmax of 25 ksi $V_{i n}, R=0.7$ and $0.001 \mathrm{~Hz}$ (Figure 4-3). The apparent, very steep initial increase in crack length for about $0.02 \mathrm{~mm}$ is probably an artifact of the change in loading from that used during the few hour equilibration of de potential drop and the start of the test.

After 50 hours, a reasonably steady state growth rate of $4.5 \times 10^{-8} \mathrm{~mm} / \mathrm{s}$ was achieved, and at 238 hours, a 3,000 s hold time at Kmax was introduced. The growth rate decreased to $2.2 \times 10^{-8} \mathrm{~mm} / \mathrm{s}$, then to $1.4 \times 10^{-8} \mathrm{~mm} / \mathrm{s}$ after the $9,000 \mathrm{~s}$ hold time was introduced at 506 hours. At 665 hours, a 85,400 hour hold time was introduced (Figure 4-4), then at 1,757 hours the loading was changed to constant $\mathrm{K}$ conditions. An initial growth rate of $5 \times 10^{-9} \mathrm{~mm} / \mathrm{s}$ was observed, which slowly decreased by about $2 \mathrm{X}$ to $2.4 \times 10^{-9} \mathrm{~mm} / \mathrm{s}$ during the remainder of the test.

At the completion of the test after 5,135 hours of exposure, the specimens were removed and broken open in fatigue. Figure 4-5 shows a macrograph of the fracture surface. The actual total crack depth was close to the 0.046 inch $(1.17 \mathrm{~mm})$ indicated by dc potential drop. The fracture surface average depth was 0.052 inch $(1.32 \mathrm{~mm})$ with a maximum of 0.058 inch $(1.47 \mathrm{~mm})$ and an approximate minimum of 0.050 inch $(1.27 \mathrm{~mm})$. The $11 \%$ error was not used to correct the crack length (nor crack growth rate) data, nor the stress intensity factor. The stress intensity factor would only have increased from $25 \mathrm{ksi}$ in to $25.4 \mathrm{ksi}$ in.

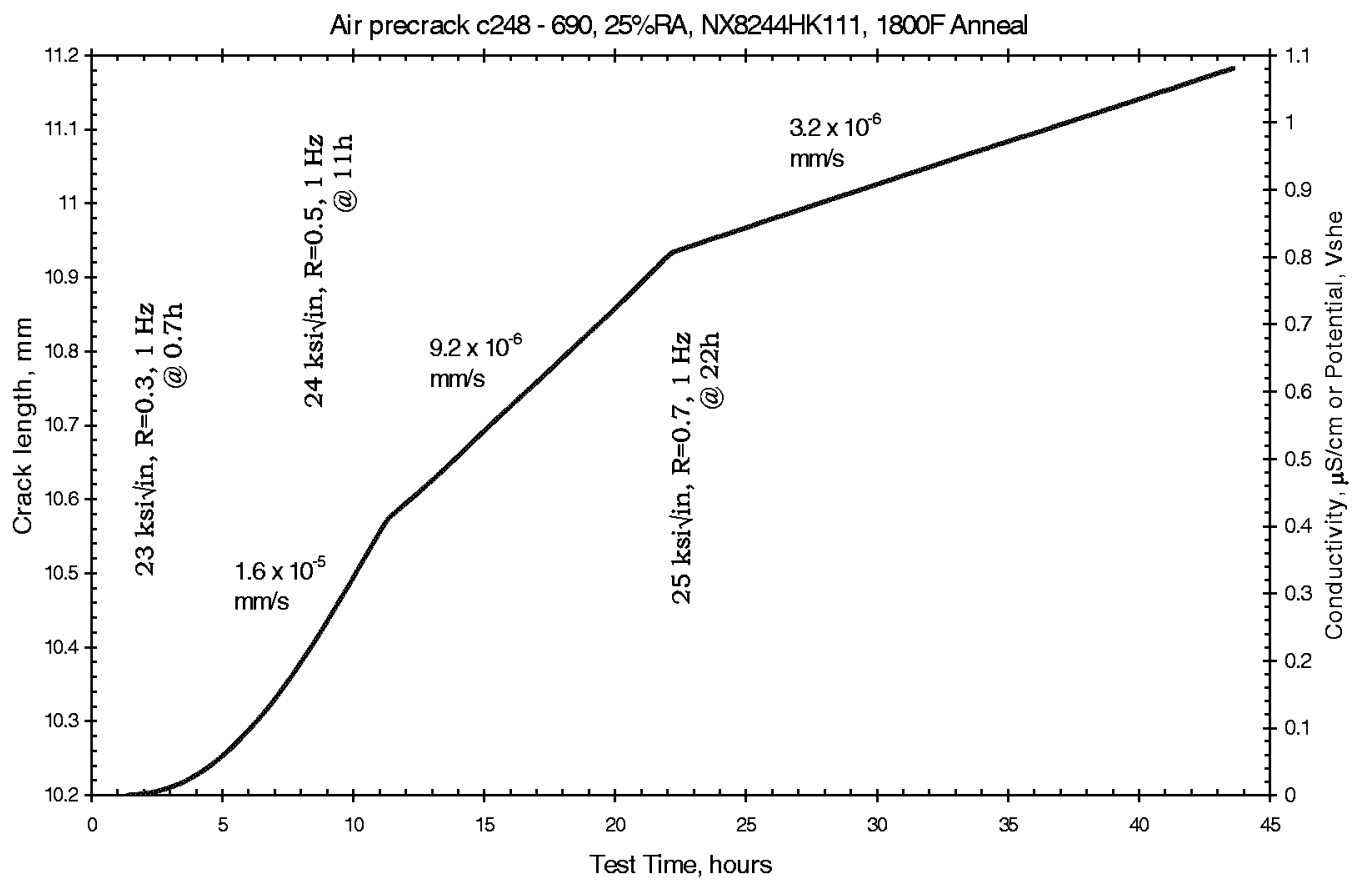

Figure 4-2

Crack Length vs. Time Response During Air Fatigue Precracking of Specimen c248 of Alloy 690 , Heat NX8244HK111 given an $1800^{\circ} \mathrm{F}$ Anneal then Forged to $25 \%$ Reduction in Thickness at $25^{\circ} \mathrm{C}$ 


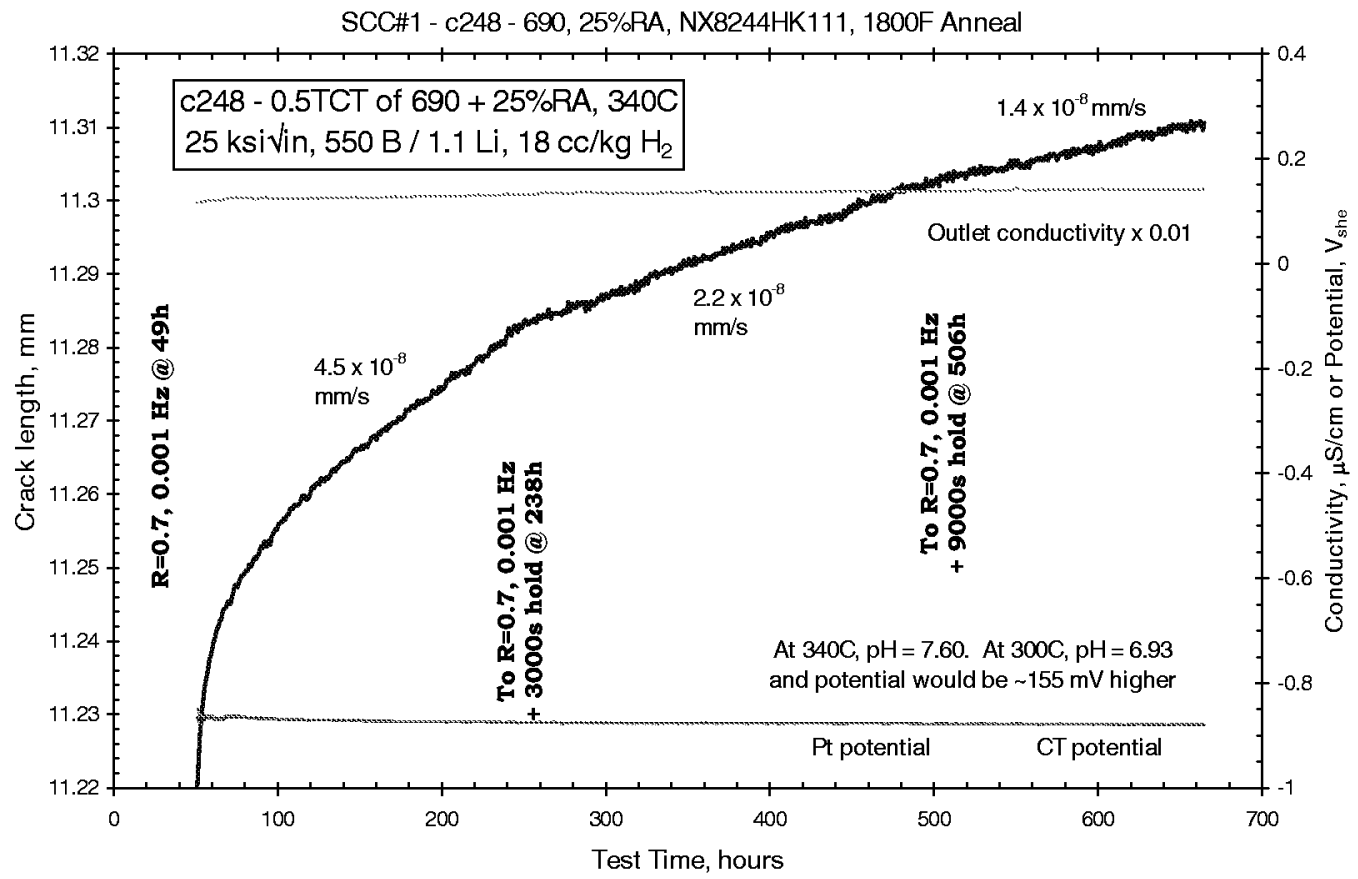

Figure 4-3

Crack Length vs. Time Response of Specimen c248 of Alloy 690, Heat NX8244HK111 given an $1800^{\circ} \mathrm{F}$ anneal then Forged to $25 \%$ Reduction in Thickness at $25^{\circ} \mathrm{C}$

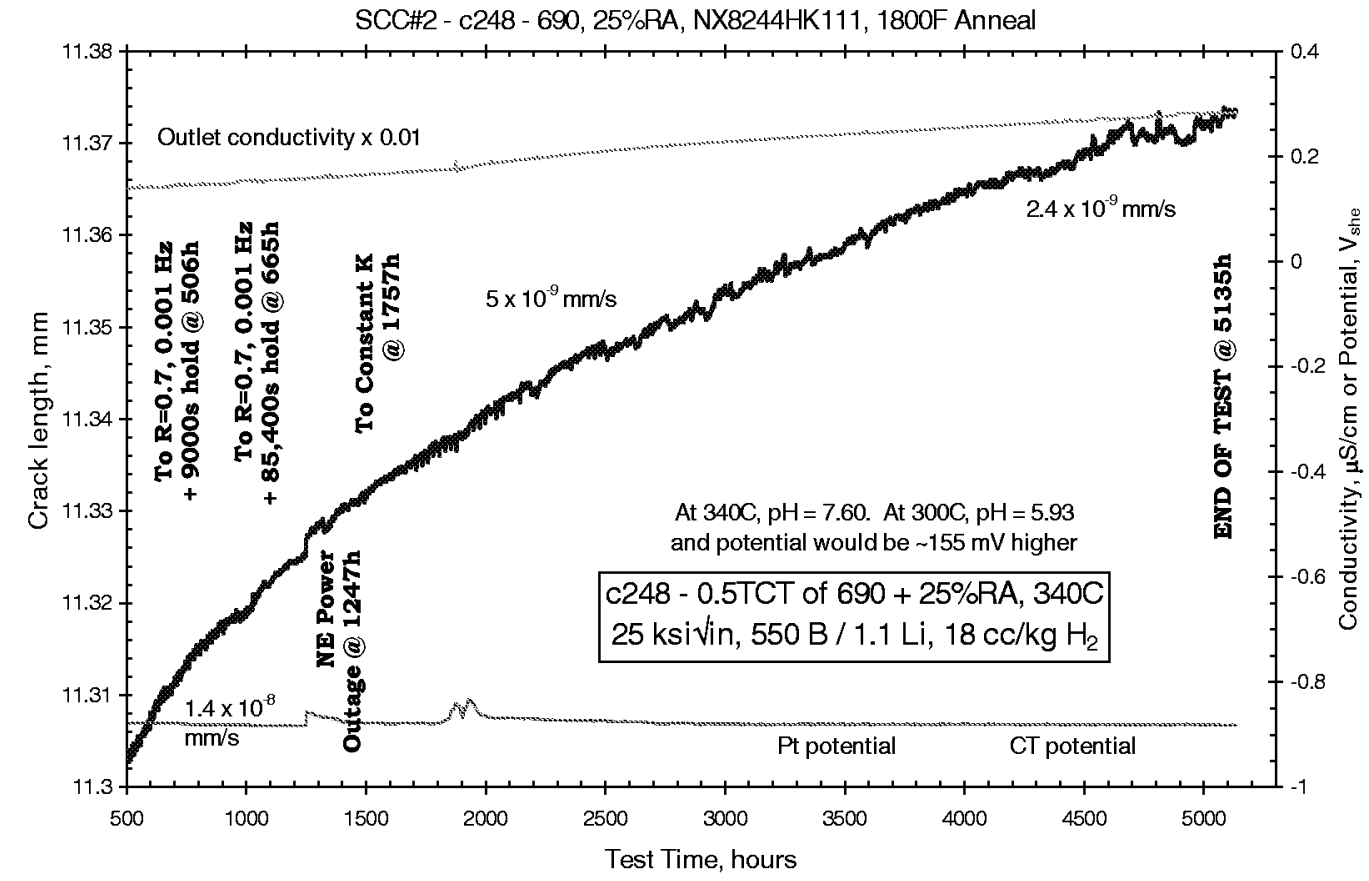

Figure 4-4

Crack Length vs. Time Response of Specimen c248 of Alloy 690, Heat NX8244HK111 given an $1800^{\circ} \mathrm{F}$ Anneal then Forged to $25 \%$ Reduction in Thickness at $25^{\circ} \mathrm{C}$ 


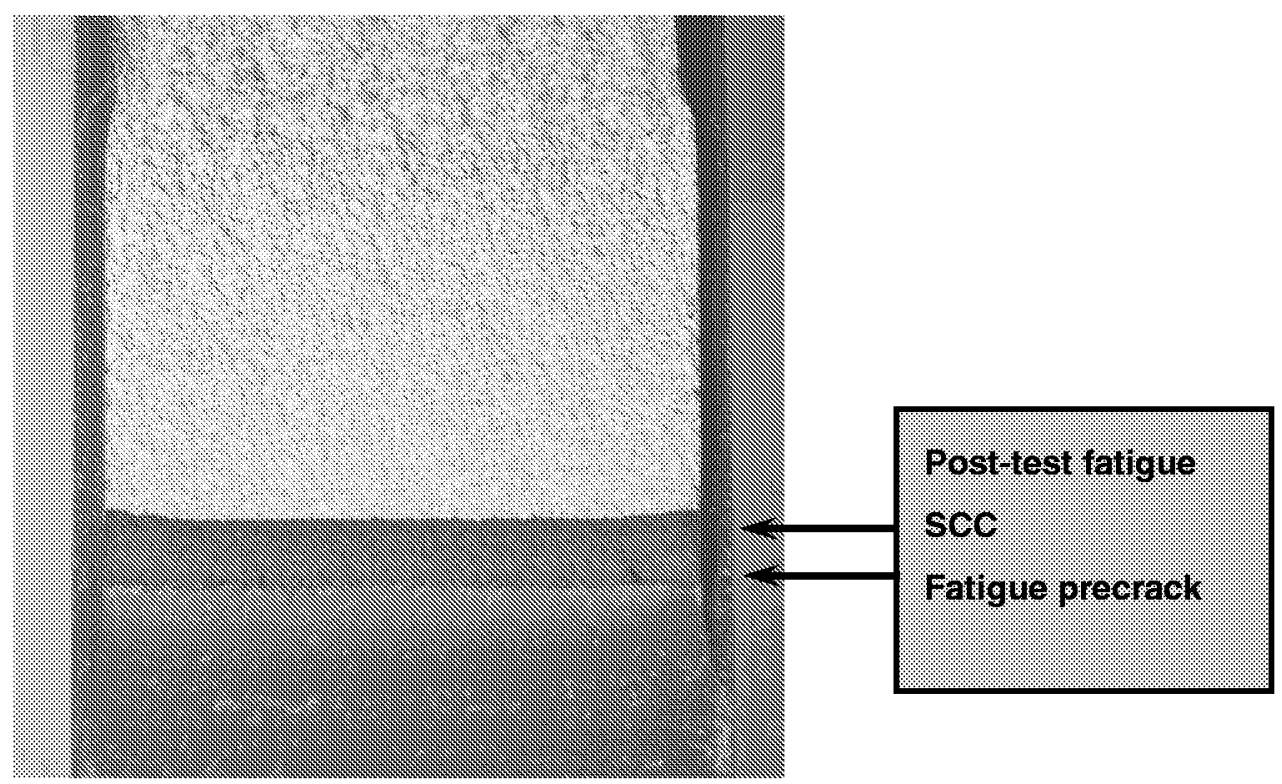

Figure 4-5

Macrograph of 0.5TCT Specimen c248 of Alloy 690, Heat NX8244HK111 given an $1800^{\circ} \mathrm{F}$ Anneal then Forged to $25 \%$ Reduction in Thickness at $25^{\circ} \mathrm{C}$

Half of the CT specimen was evaluated metallographically to examine the microstructure and the extent and type of secondary cracking which might relate to SCC (Figures 4-6 and 4-7). In this particular cross-section, there is little evidence of secondary cracking. Significant compositional banding is evident, as seen in the vertical "stripes" comprised of regions of high carbide density. There is a range of grain sizes (smaller on average than for the $2000^{\circ} \mathrm{F}$ anneal), and a lower level of grain boundary carbides.

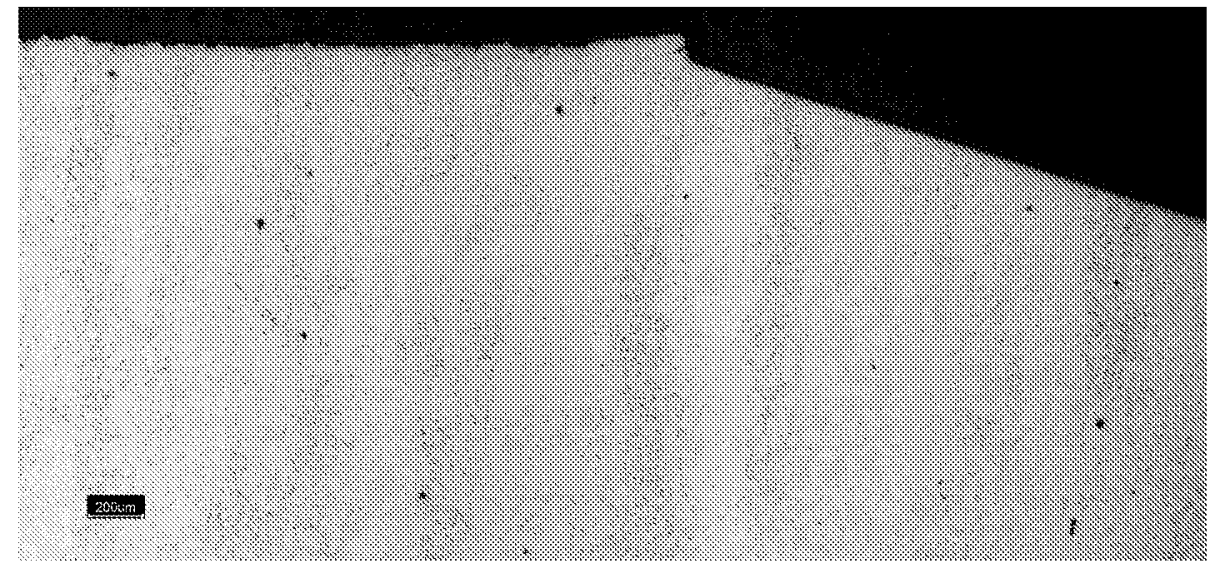

Figure 4-6

Macrograph of Cross-Sectional Metallography of 0.5TCT Specimen c248 of Alloy 690, Heat NX8244HK111, given a $1800^{\circ} \mathrm{F}$ Anneal then Forged to $25 \%$ Reduction in Thickness at $25^{\circ} \mathrm{C}$. The Machined Notch Angles up at the Upper Right, and this View Encompasses the Region of Air Fatigue Precracking and $340^{\circ} \mathrm{C} \mathrm{SCC}$. Significant Compositional Banding is Present, as Primarily Evidenced by the Vertical "Stripes" Comprised of Regions of High Carbide Density. There is a Range of Grain Sizes (Smaller on Average than for the $2000^{\circ} \mathrm{F}$ Anneal), and a Lower Level of Grain Boundary Carbides 


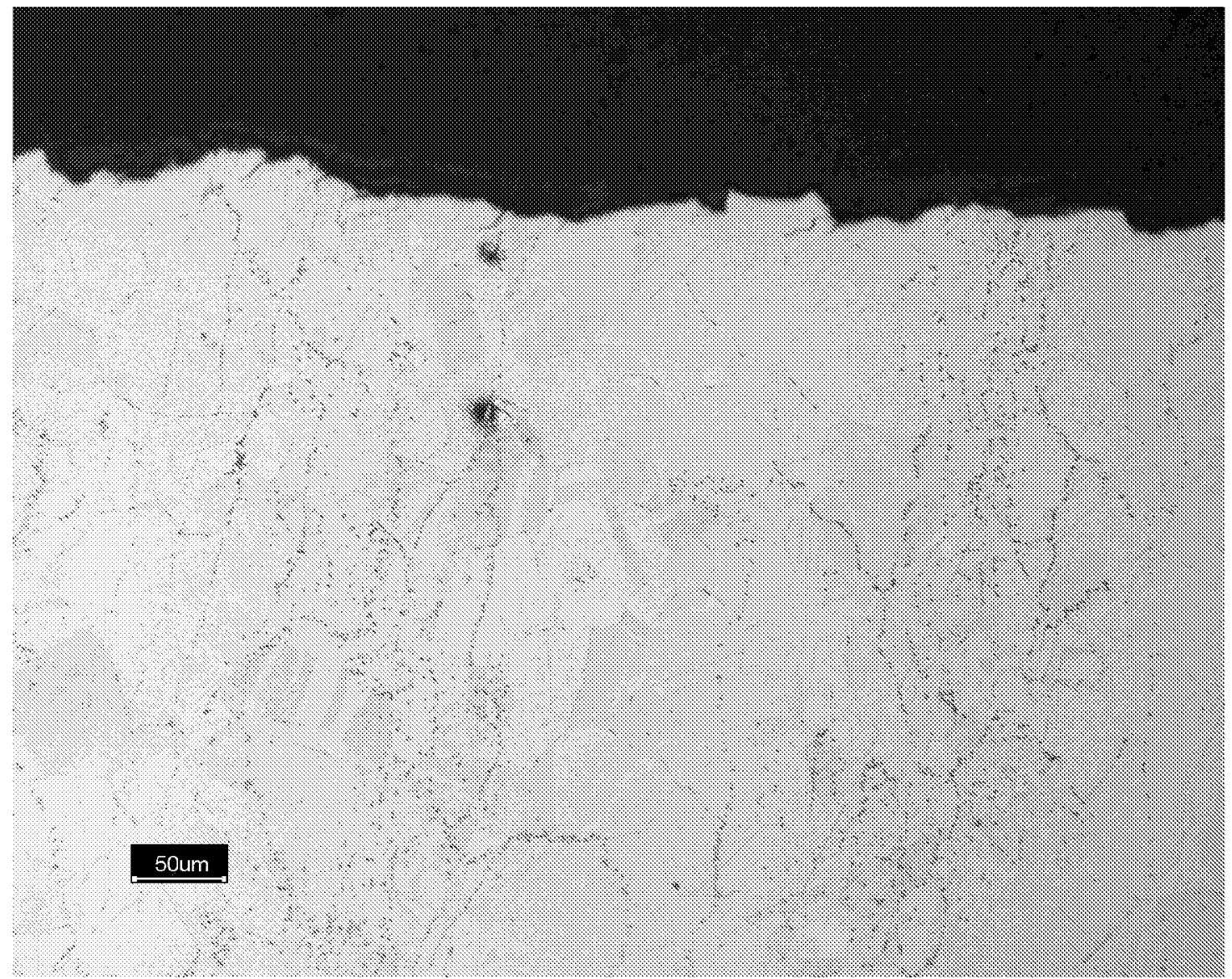

\section{Figure 4-7}

Micrograph of Cross-Sectional Metallography of 0.5TCT Specimen c248 of Alloy 690, Heat NX8244HK111, given an $1800^{\circ} \mathrm{F}$ Anneal then Forged to $25 \%$ Reduction in Thickness at $25^{\circ} \mathrm{C}$. This is a Higher Magnification View Near the End of the $340^{\circ} \mathrm{C}$ SCC Crack, which also shows the Compositional Banding and Non-Uniform Carbide Distribution

Detailed examination of the fracture surface was performed, including along the entire crack front to evaluate the evidence of intergranular cracking. Figure 4-8 shows a typical low magnification view of the fracture surface, confirming that the machined notch (toward bottom), air fatigue precrack and environmental cracking in $340^{\circ} \mathrm{C}$ water, and post-test fatigue are readily distinguishable. Because the air fatigue precrack is exposed throughout the $340^{\circ} \mathrm{C}$ test, it is difficult to delineate between the air fatigue and initial cycling during early exposure to $340^{\circ} \mathrm{C}$ water, but it is more important to be able to identify the final crack front created by the constant $\mathrm{K}$ exposure at $340^{\circ} \mathrm{C}$ - and this is very clear. Figures 4-9 to 4-12 show typical regions along the crack front. There is only very limited evidence of intergranular primary or secondary (into the fracture surface) cracking, but there is a band that appears consistently along the crack front, and it seems reasonable to interpret this as the growth that occurred during the constant $\mathrm{K}$ phase of testing. The band varies in depth between about 20 and $50 \mu \mathrm{m}$, and on average the dcpdindicated crack growth may be perhaps $50 \%$ higher, although a quantitative analysis along the entire crack front was not performed. Subsequent discussion will address the fractographic observations in more detail. 


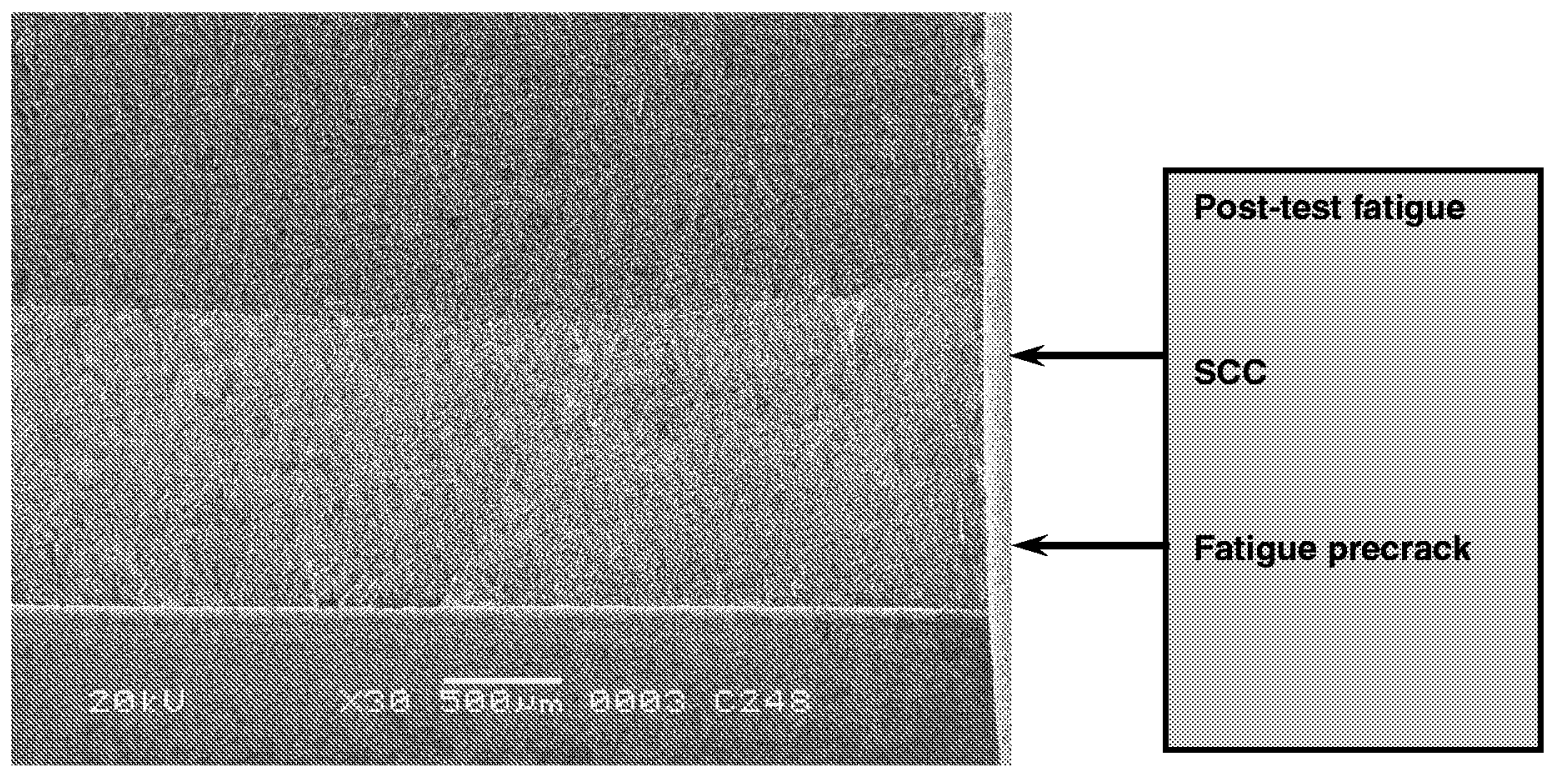

Figure 4-8

Scanning Electron Micrograph of 0.5TCT Specimen c248 of Alloy 690, Heat NX8244HK111 given an $1800^{\circ} \mathrm{F}$ Anneal then Forged to $25 \%$ Reduction in Thickness at $25^{\circ} \mathrm{C}$

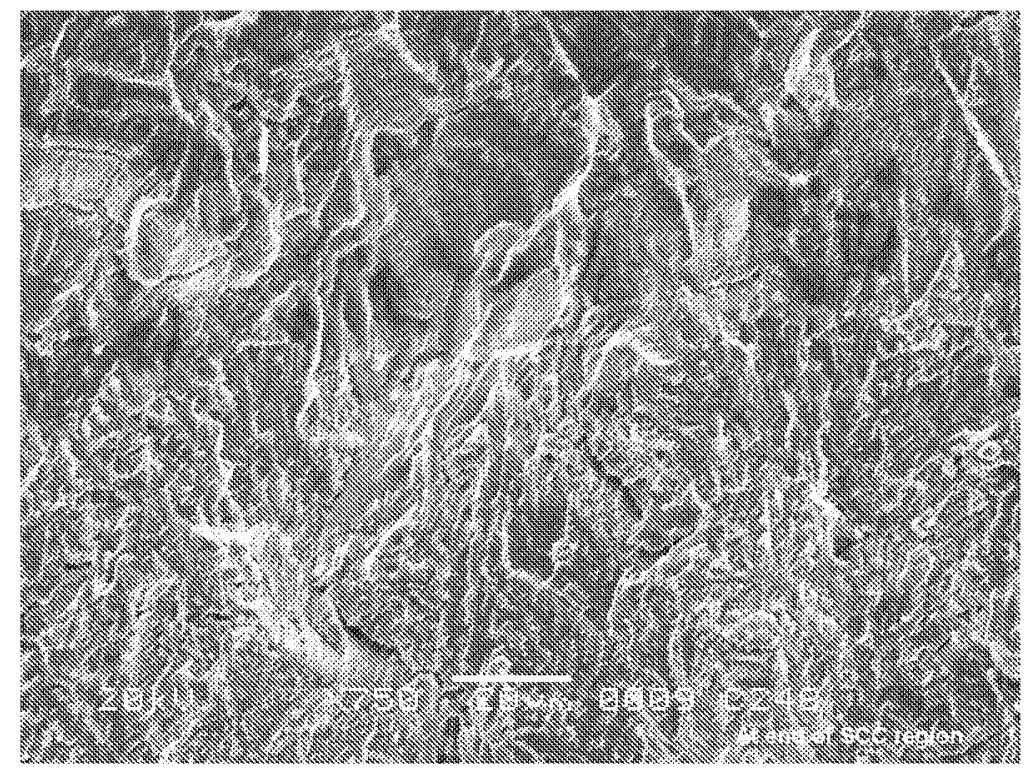

Figure 4-9

Scanning Electron Micrograph of 0.5TCT Specimen c248 of Alloy 690, Heat NX8244HK111 given an $1800^{\circ} \mathrm{F}$ Anneal then Forged to $25 \%$ Reduction in Thickness at $25^{\circ} \mathrm{C}$ 


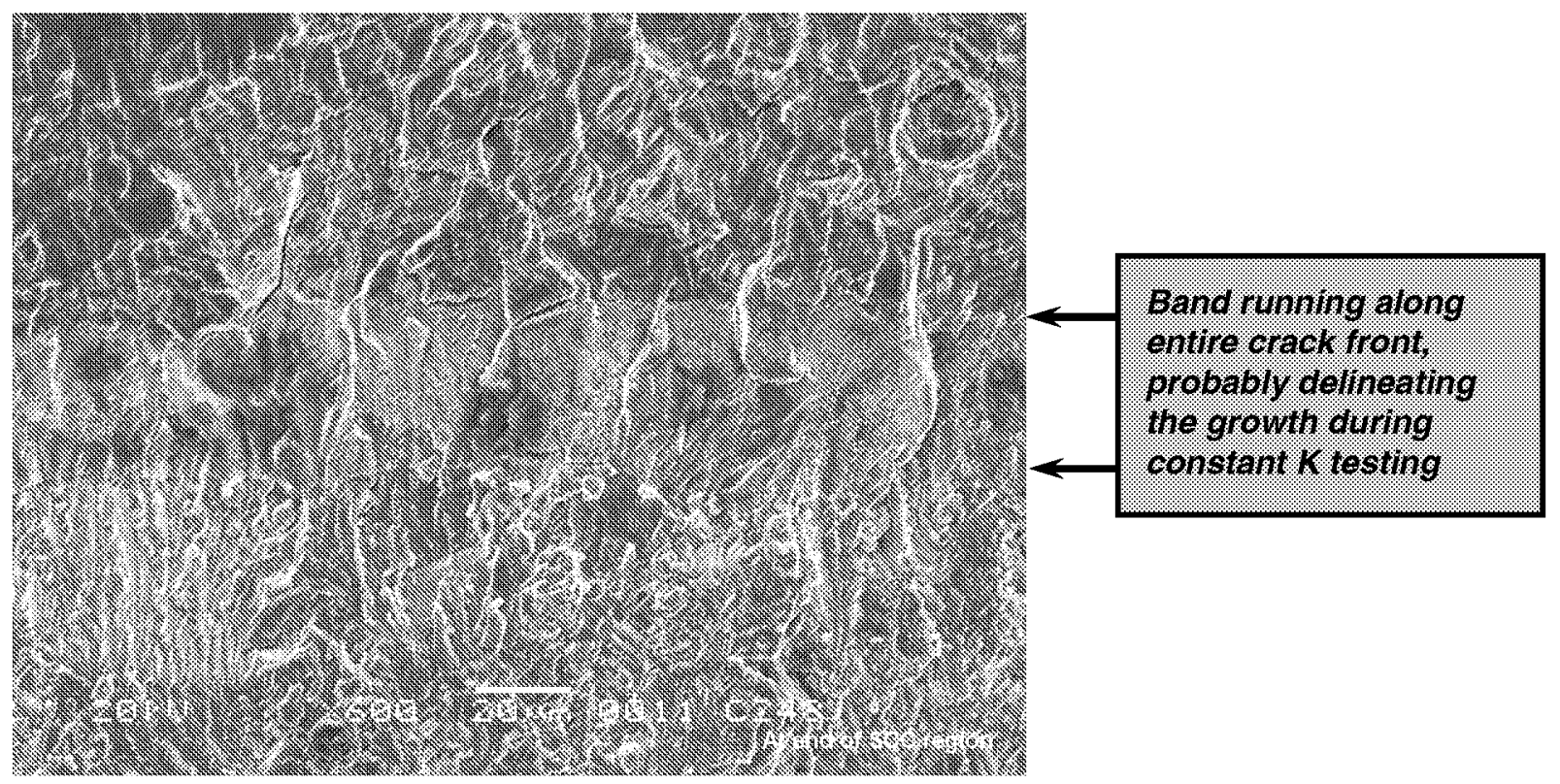

Figure 4-10

Scanning Electron Micrograph of 0.5TCT Specimen c248 of Alloy 690, Heat NX8244HK111 given an $1800^{\circ} \mathrm{F}$ Anneal then Forged to $25 \%$ Reduction in Thickness at $25^{\circ} \mathrm{C}$

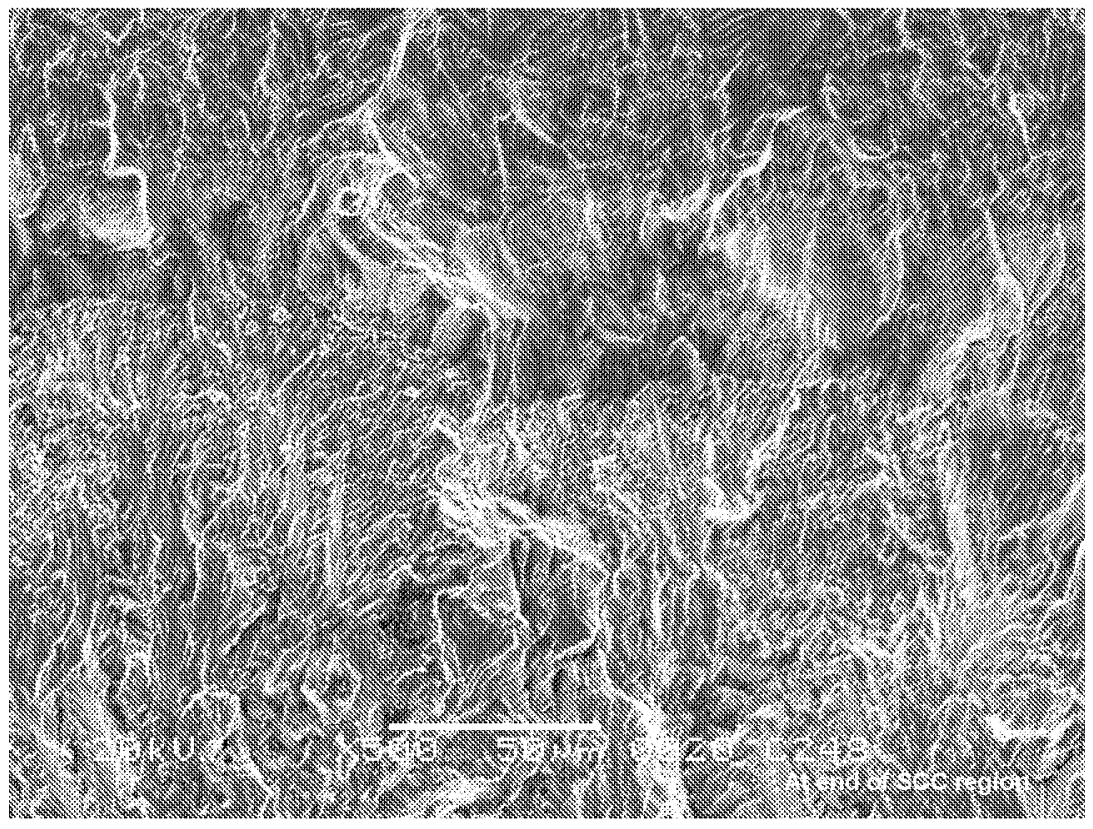

Figure 4-11

Scanning Electron Micrograph of 0.5TCT Specimen c248 of Alloy 690, Heat NX8244HK111 given an $1800^{\circ} \mathrm{F}$ Anneal then Forged to $25 \%$ Reduction in Thickness at $25^{\circ} \mathrm{C}$ 


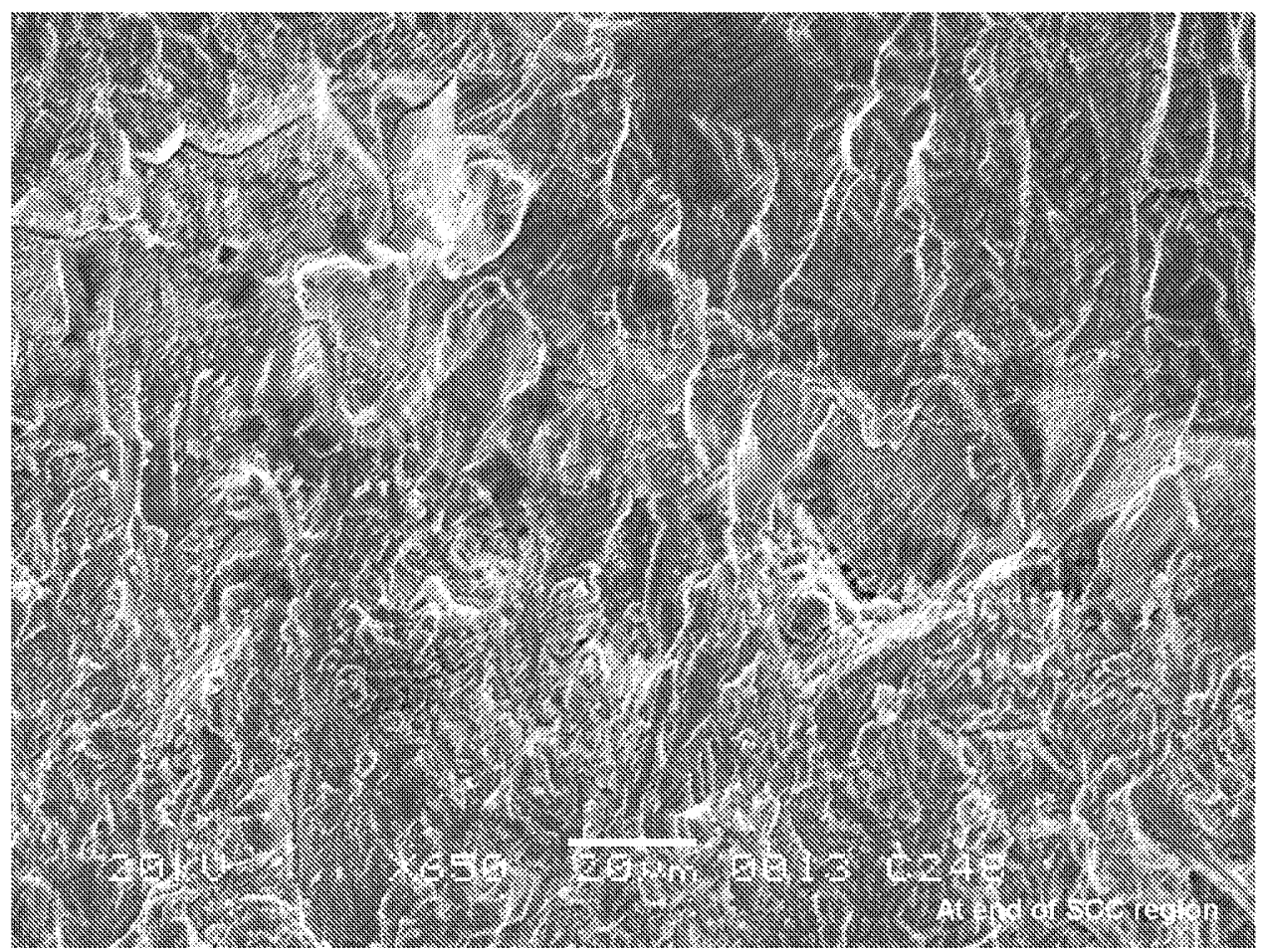

Figure 4-12

Scanning Electron Micrograph of 0.5TCT Specimen c248 of Alloy 690, Heat NX8244HK111 given an $1800^{\circ} \mathrm{F}$ Anneal then Forged to $25 \%$ Reduction in Thickness at $25^{\circ} \mathrm{C}$

\section{Specimen c249, Alloy $690,2000^{\circ} \mathrm{F}$ Anneal}

The second specimen, c249, was fabricated from the alloy 690 with the $2000^{\circ} \mathrm{F}$ anneal. For alloy 600 , such high temperature anneals generally lead to reduced susceptibility, but it's uncertain whether this applies to alloy 690. Figure 4-13 shows an overview of the test. Figure 4-14 shows the air fatigue precracking, which was performed at a variety of $\mathrm{Kmax}$ and $\Delta \mathrm{K}$ conditions. Again, the purpose is to initiate the crack from the machined notch, then shift toward the Kmax to be used in the SCC test while also increasing the load ratio, $\mathrm{R}$, thereby also approaching a $\Delta \mathrm{K}$ of zero (constant K). Figure 4-14 shows the typical crisp transitions in growth rate as the loading changes are made. All testing was performed under constant $\mathrm{K}$ conditions, so as the crack grew, load shedding occurred. 


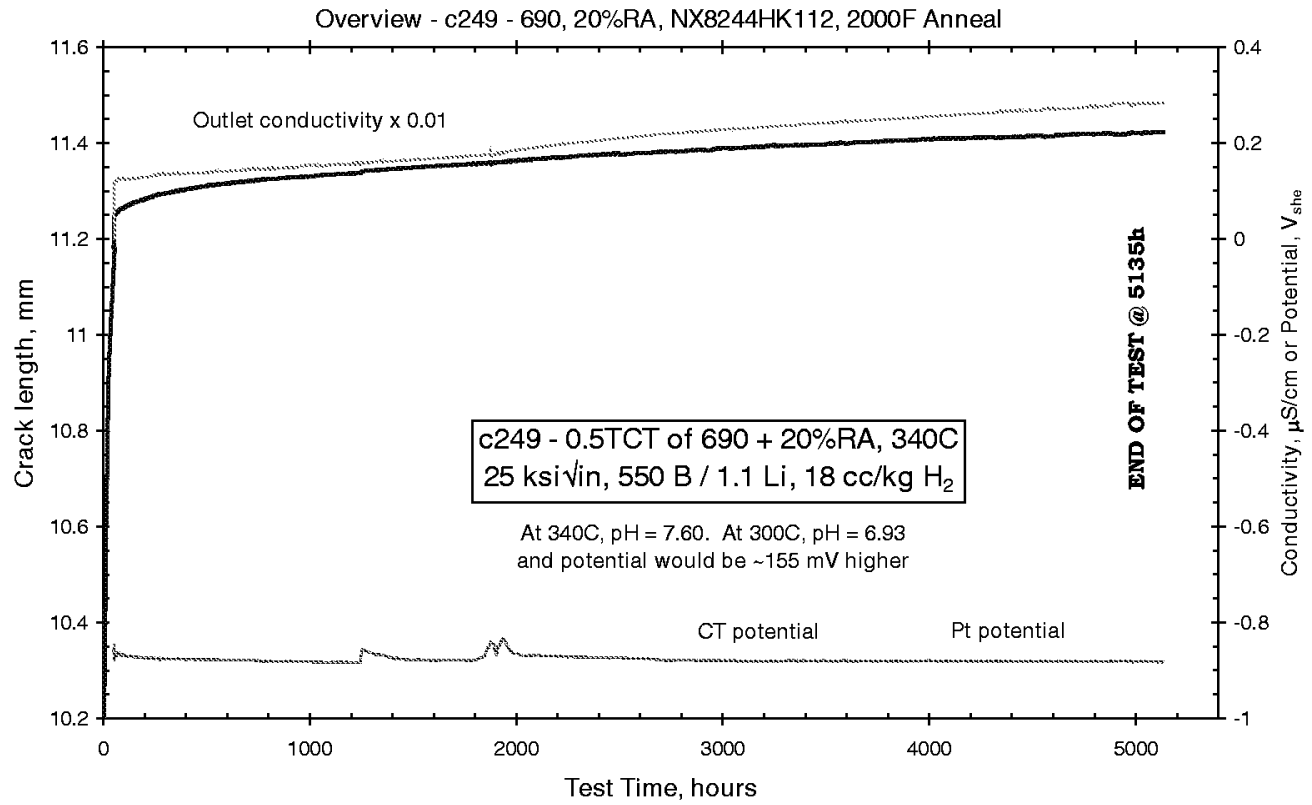

Figure 4-13

Overview of the Crack Length vs. Time Response of Specimen c249 of Alloy 690, Heat NX8244HK112 given an $2000^{\circ} \mathrm{F}$ Anneal then Forged to $20 \%$ Reduction in Thickness at $25^{\circ} \mathrm{C}$

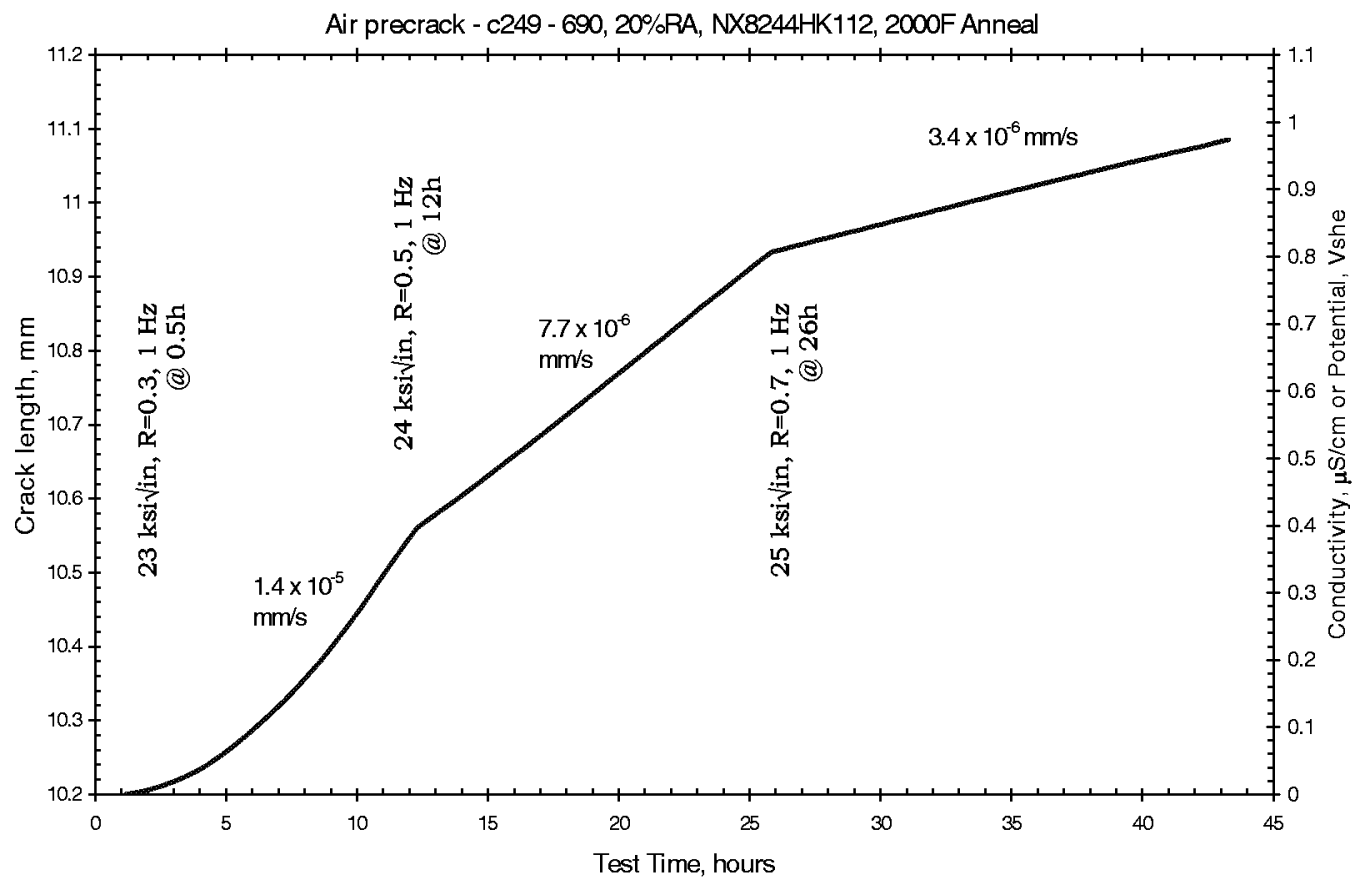

Figure 4-14

Crack Length vs. Time Response During Air Fatigue Precracking of Specimen c249 of Alloy 690 , Heat NX8244HK112 given an $2000^{\circ} \mathrm{F}$ Anneal then Forged to $20 \%$ Reduction in Thickness at $25^{\circ} \mathrm{C}$ 
Specimen c249 was then assembled into the autoclave together with specimen c248 and the environmental conditions established as described earlier. The system was allowed to equilibrate for a few days, then the specimens were loaded at a Kmax of $25 \mathrm{ksi} \mathrm{Vin}_{\mathrm{in}} \mathrm{R}=0.7$ and $0.001 \mathrm{~Hz}$ (Figure 4-15). The very steep initial increase in crack length for about $0.02 \mathrm{~mm}$ is probably an artifact of the change in loading from that used during the few hour equilibration of de potential drop and the start of the test.

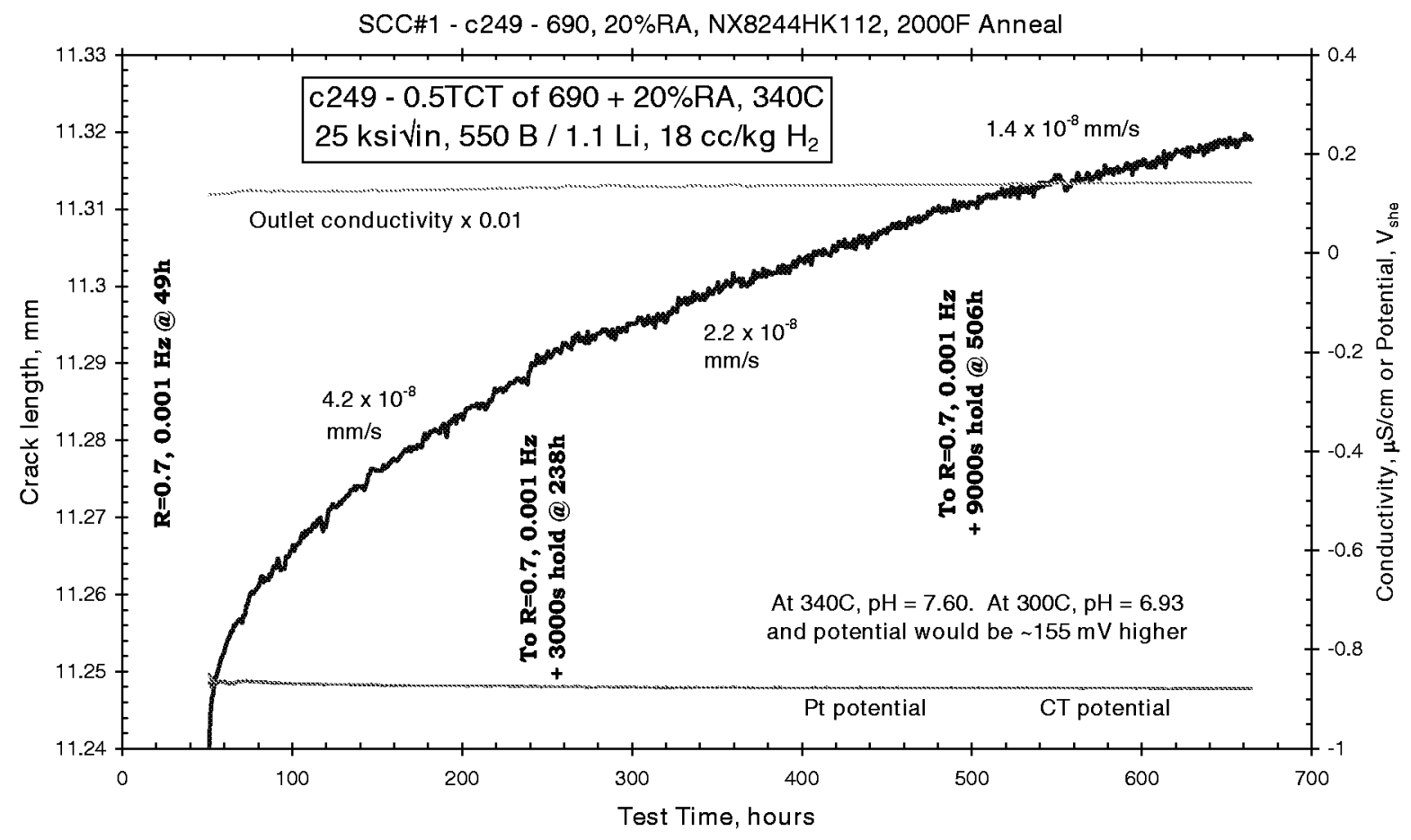

\section{Figure 4-15 \\ Crack Length vs. Time Response of Specimen c249 of Alloy 690, Heat NX8244HK112 given an $2000^{\circ} \mathrm{F}$ Anneal then Forged to $20 \%$ Reduction in Thickness at $25^{\circ} \mathrm{C}$}

After 50 hours, a reasonably steady state growth rate of $4.2 \times 10^{-8} \mathrm{~mm} / \mathrm{s}$ was achieved, and at 238 hours, a 3,000 s hold time at Kmax was introduced. The growth rate decreased to $2.2 \times 10^{-8}$ $\mathrm{mm} / \mathrm{s}$, then to $1.4 \times 10^{-8} \mathrm{~mm} / \mathrm{s}$ after the $9,000 \mathrm{~s}$ hold time was introduced at 506 hours. At 665 hours, a 85,400 hour hold time was introduced (Figure 4-16), then at 1,757 hours the loading was changed to constant $\mathrm{K}$ conditions. An initial growth rate of $8 \times 10^{-9} \mathrm{~mm} / \mathrm{s}$ was observed, which slowly decreased by about $2 \mathrm{X}$ to $3.7 \times 10^{-9} \mathrm{~mm} / \mathrm{s}$ during the remainder of the test. 


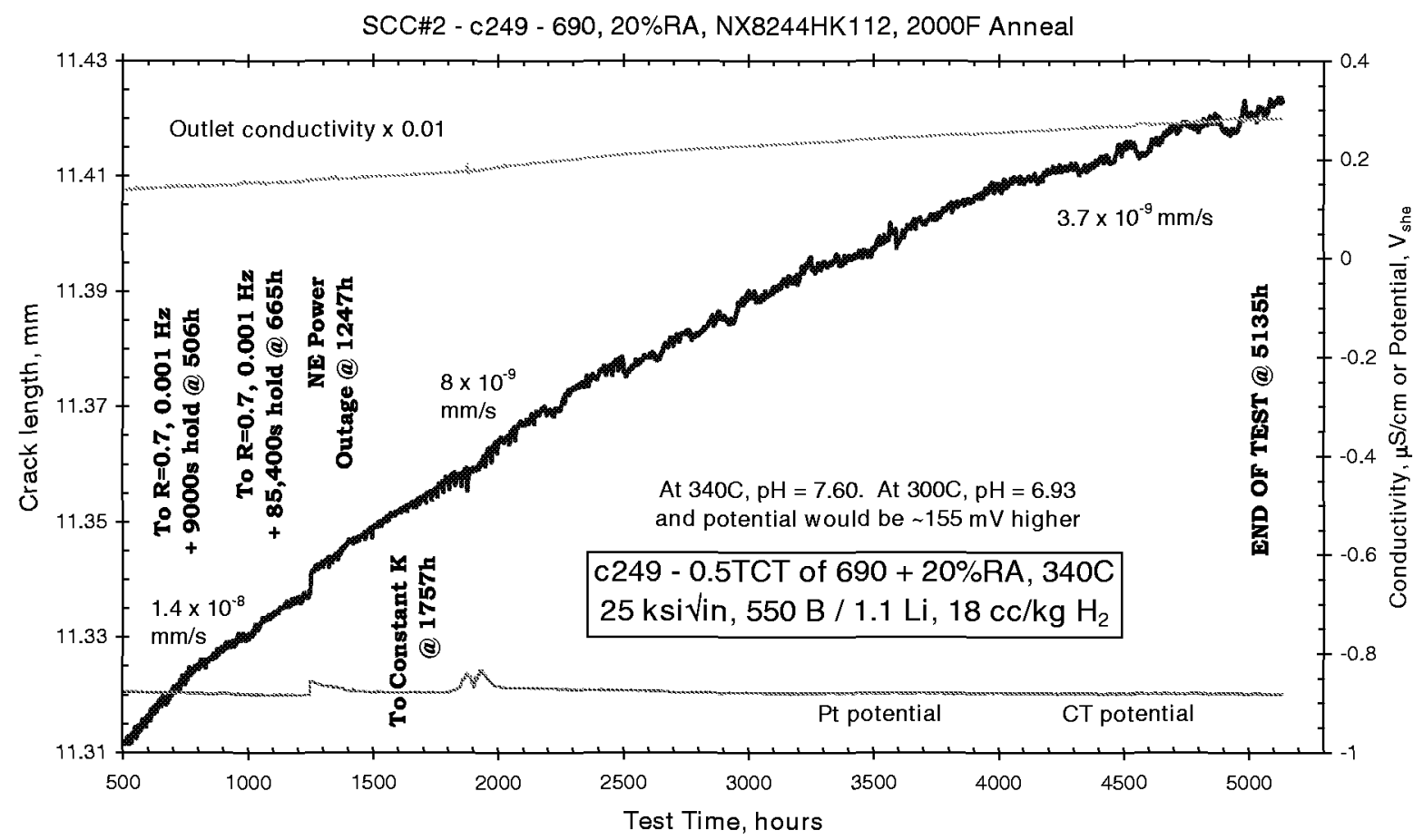

Figure 4-16

Crack Length vs. Time Response of Specimen c249 of Alloy 690, Heat NX8244HK112 given an $2000^{\circ} \mathrm{F}$ Anneal then Forged to $20 \%$ Reduction in Thickness at $25^{\circ} \mathrm{C}$

The test was ended at 5,135 hours, and the specimens were removed and fatigued apart.

Figure 4-17 shows a macrograph of the fracture surface. The actual depth of stress corrosion crack was close to the 0.048 inch $(1.22 \mathrm{~mm})$ indicated by dc potential drop. The average fracture surface depth was 0.050 inch $(1.27 \mathrm{~mm})$ with a maximum of 0.064 inch $(1.63 \mathrm{~mm})$ and an approximate minimum of 0.043 inch $(1.09 \mathrm{~mm})$. The $4 \%$ error was somewhat less than in specimen c248, and was not used to correct the crack length (nor crack growth rate) data, nor the stress intensity factor. The stress intensity factor would only have increased from $25 \mathrm{ksi}$ in to $25.1 \mathrm{ksi} \sqrt{i n}$. Note also that the crack depths for the two specimens remained very close throughout the test, so that while the loading was controlled based on the response of specimen c248, the stress intensity factor on specimen c249 was essentially identical. 


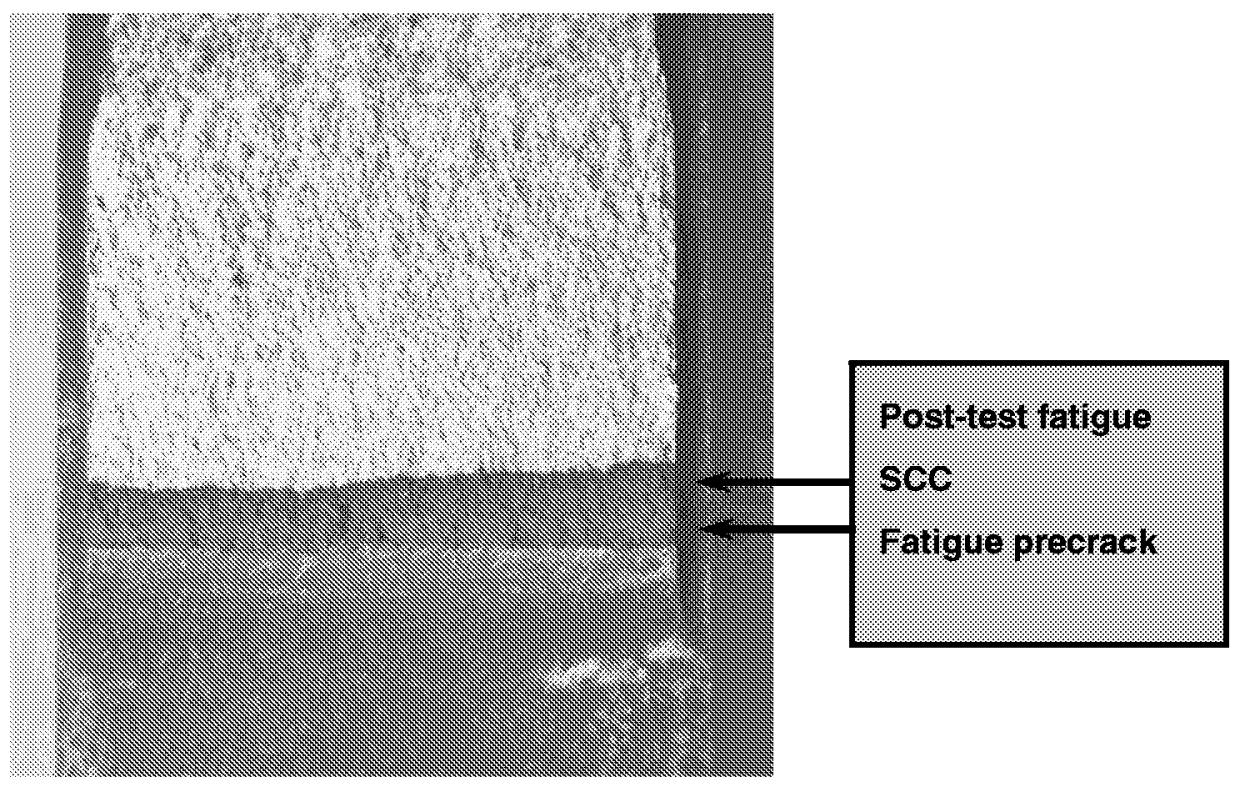

Figure 4-17

Macrograph of 0.5TCT Specimen c249 of Alloy 690, Heat NX8244HK111, given a $2000^{\circ} \mathrm{F}$ Anneal then Forged to $20 \%$ Reduction in Thickness at $25^{\circ} \mathrm{C}$

Half of the CT specimen was evaluated metallographically to examine the microstructure and the extent and type of secondary cracking (Figures 4-18 and 4-19). There is little evidence of intergranular cracking in this particular cross-section, although it is clear that there some transgranular secondary cracks are present. There is less compositional banding than in specimen c248 (Figures 4-6 and 4-7) and the grain size is larger and more uniform than in the material annealed at $1800^{\circ} \mathrm{F}$; there are also more grain boundary carbides.

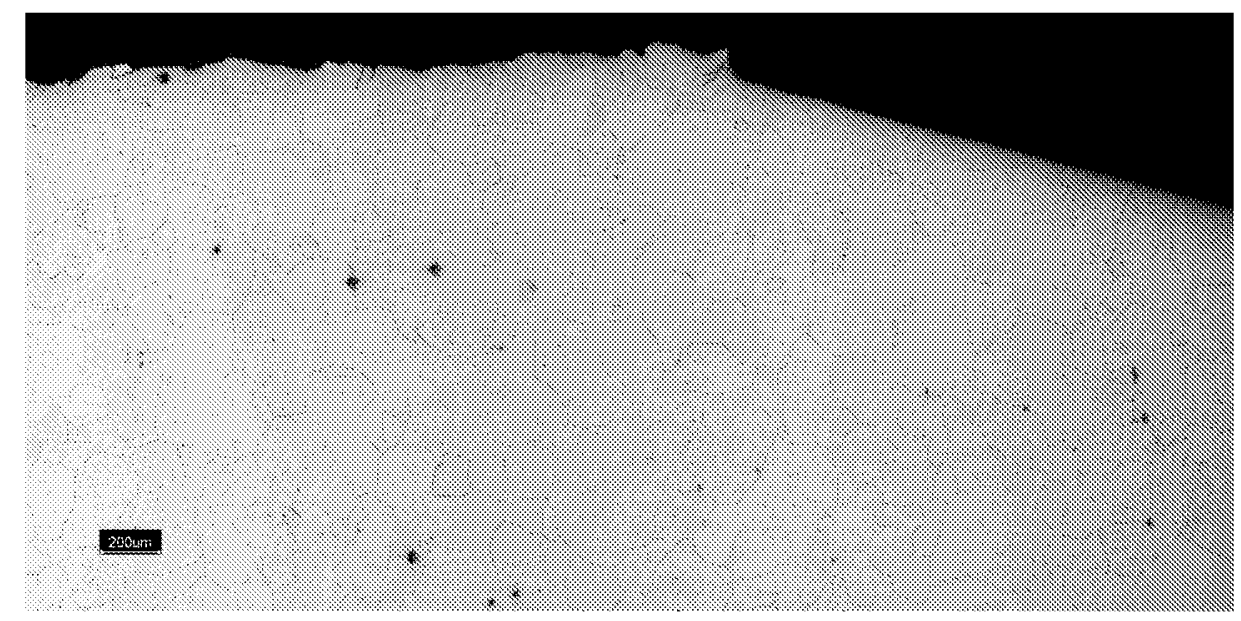

Figure 4-18

Macrograph of Cross-Sectional Metallography of 0.5TCT Specimen c249 of Alloy 690, Heat NX8244HK111, given a $2000^{\circ} \mathrm{F}$ Anneal then Forged to $20 \%$ Reduction in Thickness at $25^{\circ} \mathrm{C}$. The Machined Notch Angles up at the Upper Right, and this View Encompasses the Region of Air Fatigue Precracking and $340^{\circ} \mathrm{C} \mathrm{SCC}$. Compositional Banding is Dramatically Less than in c248 ( $1800^{\circ} \mathrm{F}$ Anneal). The Grain Sizes is also more Uniform, and the Density of Grain Boundary Carbides is Higher 


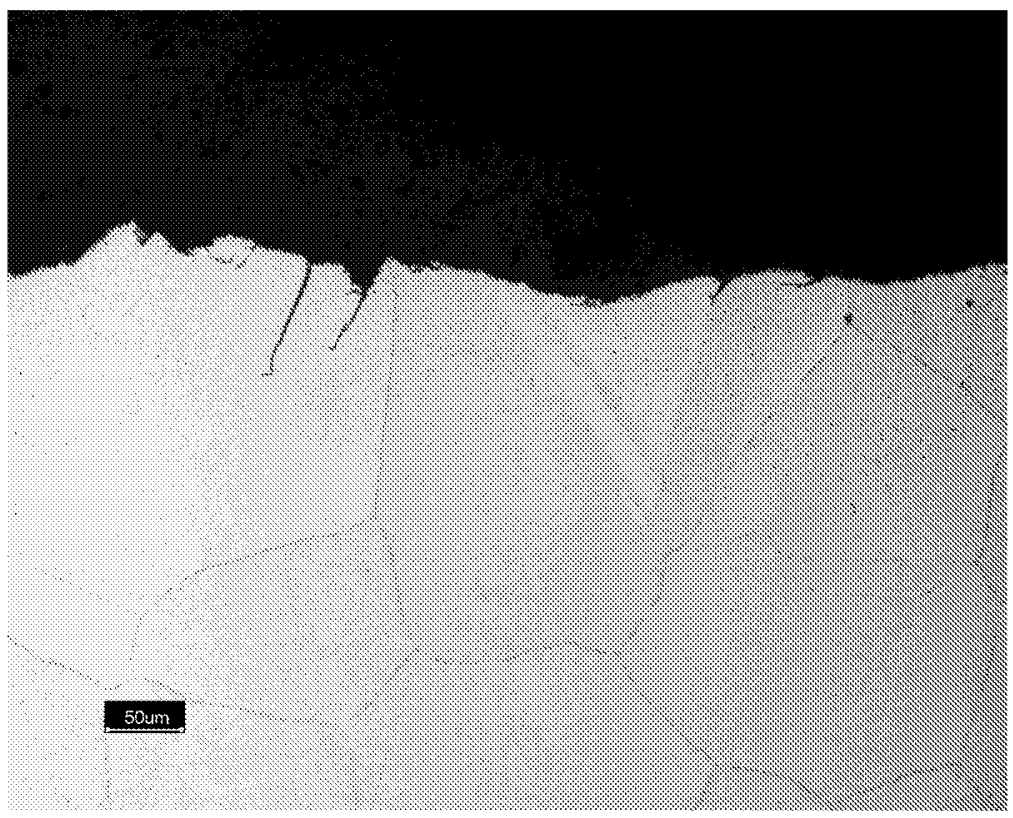

Figure 4-19

Micrograph of Cross-Sectional Metallography of 0.5TCT Specimen c249 of Alloy 690, Heat NX8244HK111, given a $2000^{\circ} \mathrm{F}$ Anneal then Forged to $20 \%$ Reduction in Thickness at $25^{\circ} \mathrm{C}$. This is a Higher Magnification View Near the End of the $340^{\circ} \mathrm{C} \mathrm{SCC} \mathrm{Crack}$

The fracture surface was examined in detail. In particular, the entire crack front was scanned for evidence of intergranular cracking. A typical low magnification view of the fracture surface is shown in Figure 4-20 and confirms that the machined notch (toward bottom), air fatigue precrack and environmental cracking in $340^{\circ} \mathrm{C}$ water, and post-test fatigue are readily distinguishable. Because the air fatigue precrack is exposed throughout the $340^{\circ} \mathrm{C}$ test, it is again difficult to delineate between the air fatigue and initial cycling during early exposure to $340^{\circ} \mathrm{C}$ water, but more important to be able to identify the final crack front created by the constant $\mathrm{K}$ exposure at $340^{\circ} \mathrm{C}$. Figures 4-21 to 4-24 show typical regions along the crack front. There is only very limited evidence of intergranular primary or secondary (into the fracture surface) cracking, but there is a band that appears consistently along the crack front (particularly clear in Figures 4-21 and 4-22), and it seems reasonable to interpret this as the growth that occurred during the constant $\mathrm{K}$ phase of testing. The band varies in depth between about 20 and $50 \mu \mathrm{m}$, and on average the depd-indicated crack growth may be perhaps $75 \%$ higher, although a quantitative analysis along the entire crack front was not performed. These fractographic observations will be discussed in more detail later. 


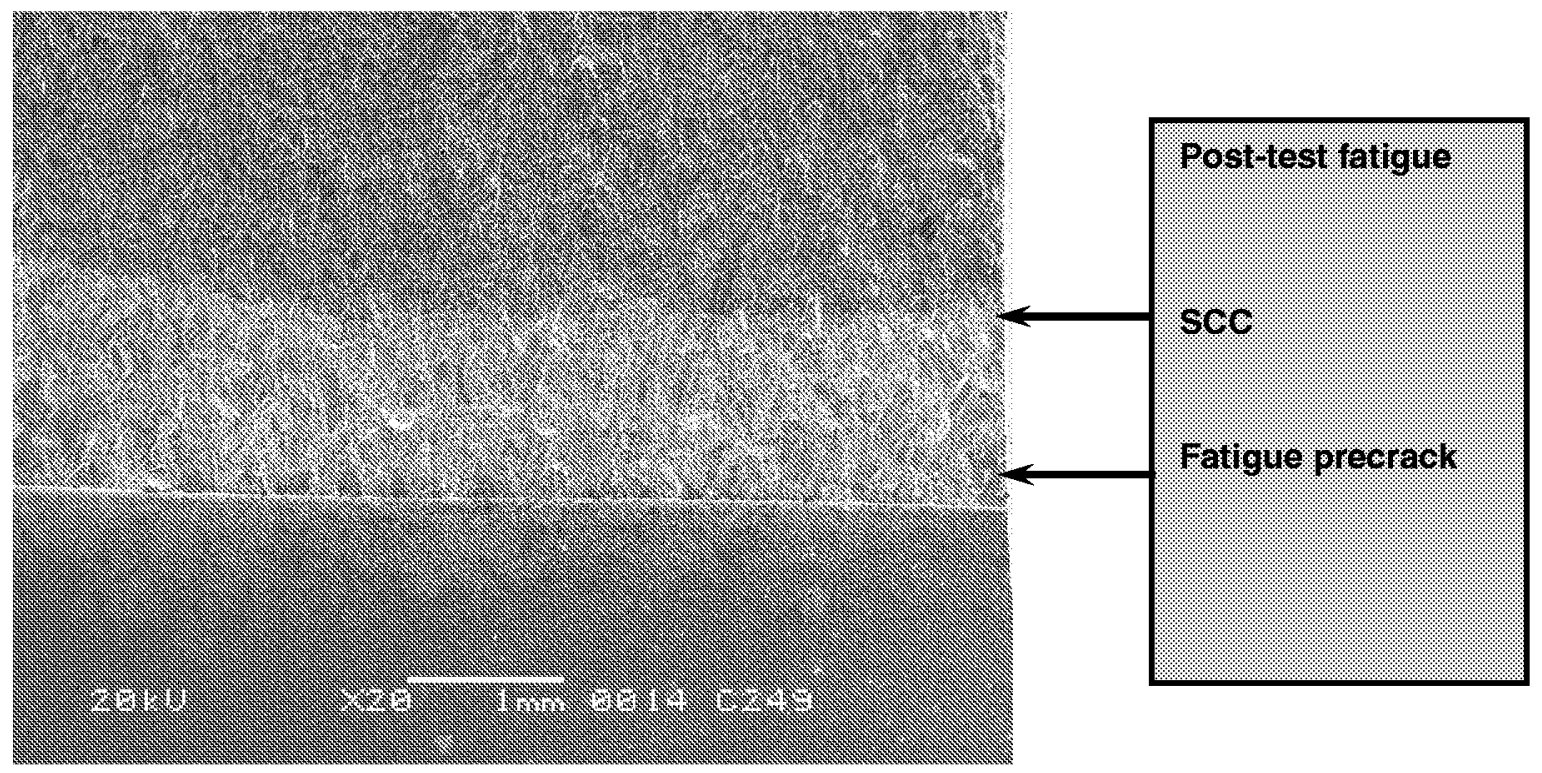

Figure 4-20

Scanning Electron Micrograph of 0.5TCT Specimen c249 of Alloy 690, Heat NX8244HK111, given a $2000^{\circ} \mathrm{F}$ Anneal then Forged to $20 \%$ Reduction in Thickness at $25^{\circ} \mathrm{C}$

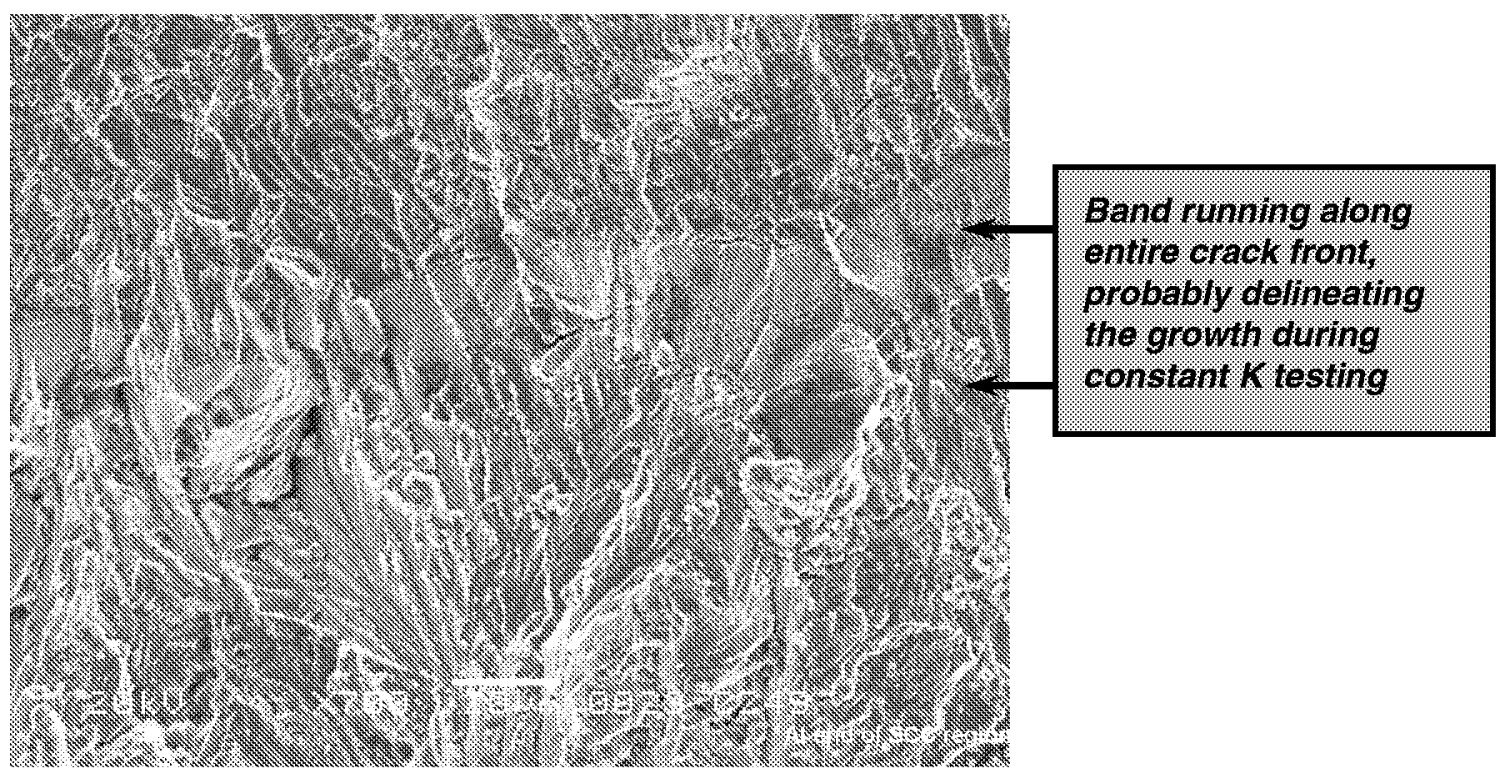

Figure 4-21

Scanning Electron Micrograph of 0.5TCT Specimen c249 of Alloy 690, Heat NX8244HK111, given a $2000^{\circ} \mathrm{F}$ Anneal then Forged to $20 \%$ Reduction in Thickness at $25^{\circ} \mathrm{C}$ 


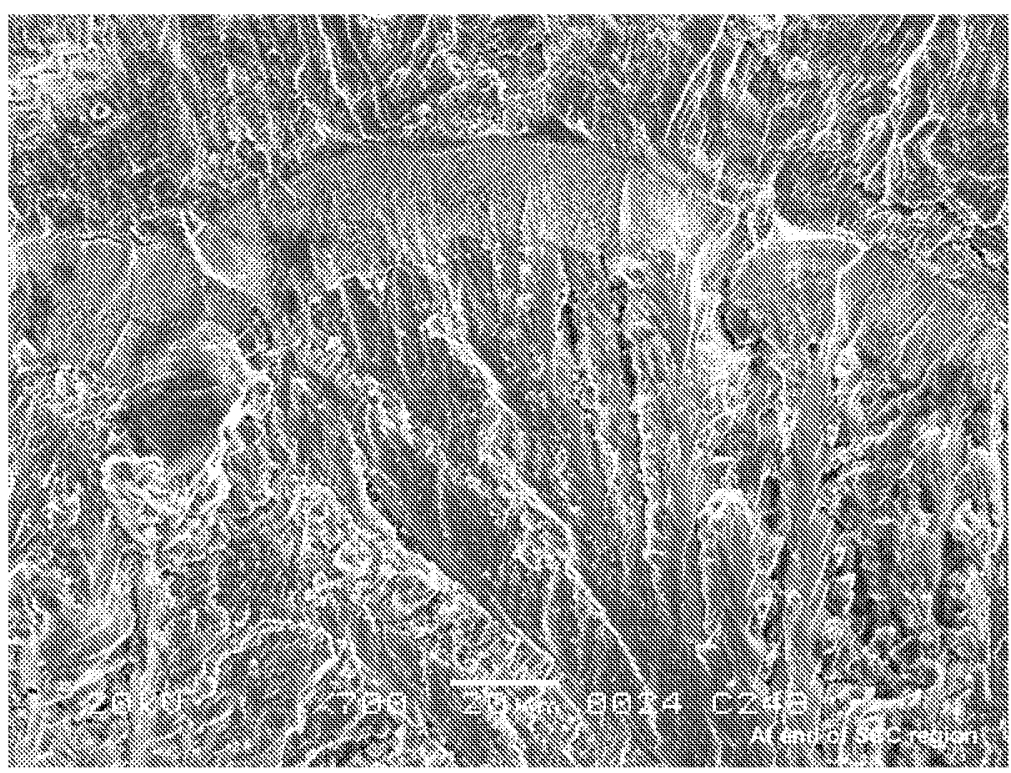

Figure 4-22

Scanning Electron Micrograph of 0.5TCT Specimen c249 of Alloy 690, Heat NX8244HK111, given a $2000^{\circ} \mathrm{F}$ Anneal then Forged to $20 \%$ Reduction in Thickness at $25^{\circ} \mathrm{C}$

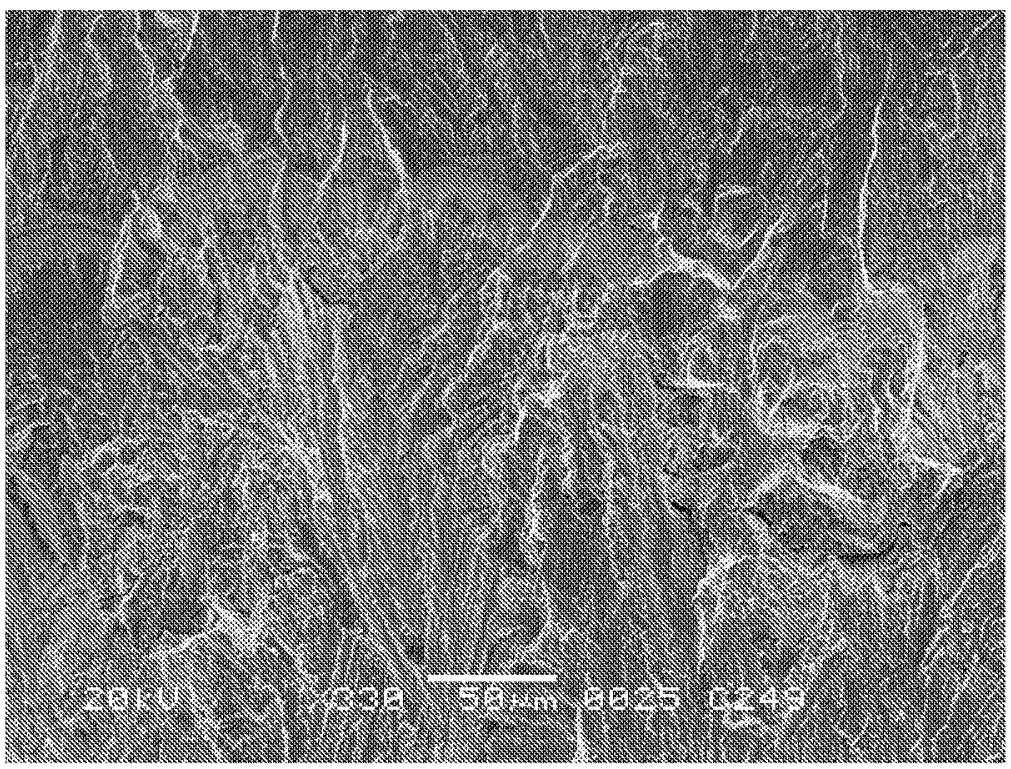

Figure 4-23

Scanning Electron Micrograph of 0.5TCT Specimen c249 of Alloy 690, Heat NX8244HK111, given a $2000^{\circ} \mathrm{F}$ Anneal then Forged to $20 \%$ Reduction in Thickness at $25^{\circ} \mathrm{C}$ 


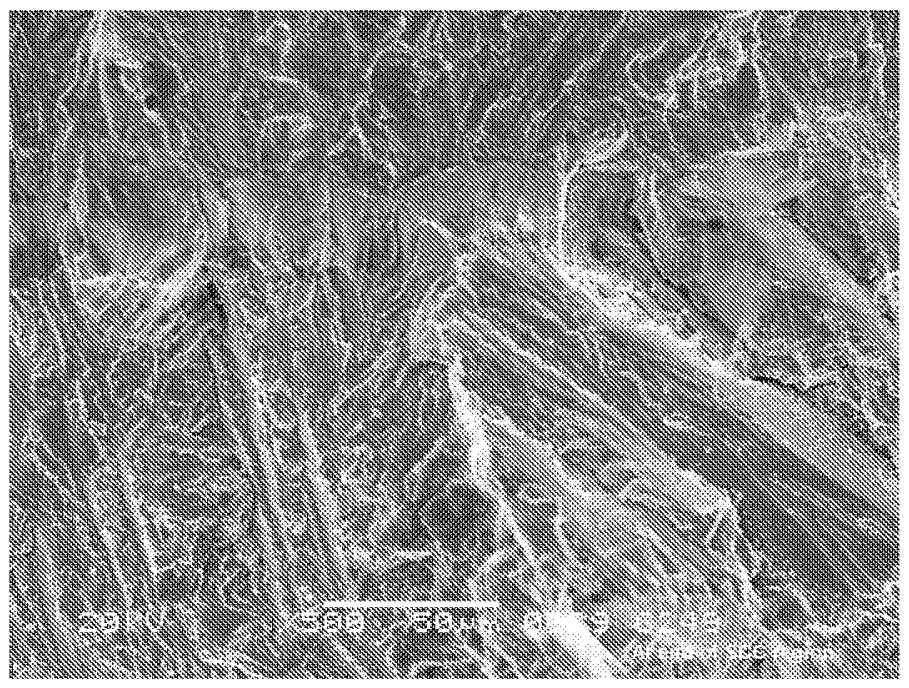

Figure 4-24

Scanning Electron Micrograph of 0.5TCT Specimen c249 of Alloy 690, Heat NX8244HK111, given a $2000^{\circ} \mathrm{F}$ Anneal then Forged to $20 \%$ Reduction in Thickness at $25^{\circ} \mathrm{C}$

\section{Comparison and Interpretation of Crack Growth Rate Data}

Throughout precracking and SCC testing, these two specimens responded very similarly (see Table 4-1), as should be the case for nearly identical specimens (the primary difference is the final annealing temperature as well as a small difference in the amount of reduction in thickness).

Indeed, the similarity in their response argues against a large effect of the final annealing temperature although, if anything, it suggests the high temperature anneal may be slightly more susceptible given its slightly higher growth rates and slightly lower cold work. However, neither the difference in growth rate nor in cold work (whose effect on SCC is neither linear with either cold work nor yield strength) is enough to be noteworthy.

Table 4-1

Crack Growth Rates Measured during Fatigue Pre-Cracking and SCC Testing

\begin{tabular}{|l|c|c|}
\hline \multicolumn{1}{|c|}{ Crack Growth Rate, $\mathbf{m m} / \mathbf{s}$} & c248 & c249 \\
\hline Air, R=0.3 & $1.6 \times 10^{-5} \mathrm{~mm} / \mathrm{s}$ & $1.4 \times 10^{-5} \mathrm{~mm} / \mathrm{s}$ \\
\hline Air, R=0.5 & $9.2 \times 10^{-6} \mathrm{~mm} / \mathrm{s}$ & $7.7 \times 10^{-6} \mathrm{~mm} / \mathrm{s}$ \\
\hline Air, R=0.7 & $3.2 \times 10^{-6} \mathrm{~mm} / \mathrm{s}$ & $3.4 \times 10^{-6} \mathrm{~mm} / \mathrm{s}$ \\
\hline $340^{\circ} \mathrm{C}, 0.001 \mathrm{~Hz}$ & $4.5 \times 10^{-8} \mathrm{~mm} / \mathrm{s}$ & $4.2 \times 10^{-8} \mathrm{~mm} / \mathrm{s}$ \\
\hline $340^{\circ} \mathrm{C}, 3000 \mathrm{~s}$ hold & $2.2 \times 10^{-8} \mathrm{~mm} / \mathrm{s}$ & $2.2 \times 10^{-8} \mathrm{~mm} / \mathrm{s}$ \\
\hline $340^{\circ} \mathrm{C}, 9000 \mathrm{~s}$ hold & $1.4 \times 10^{-8} \mathrm{~mm} / \mathrm{s}$ & $1.4 \times 10^{-8} \mathrm{~mm} / \mathrm{s}$ \\
\hline $340^{\circ} \mathrm{C}, 85400 \mathrm{~s}$ hold & $7 \times 10^{-9} \mathrm{~mm} / \mathrm{s}$ & $1 \times 10^{-8} \mathrm{~mm} / \mathrm{s}$ \\
\hline $340^{\circ} \mathrm{C}$, constant $\mathrm{K}$, initial & $5 \times 10^{-9} \mathrm{~mm} / \mathrm{s}$ & $8 \times 10^{-9} \mathrm{~mm} / \mathrm{s}$ \\
\hline $340^{\circ} \mathrm{C}$, constant $\mathrm{K}$, later & $2.4 \times 10^{-9} \mathrm{~mm} / \mathrm{s}$ & $3.7 \times 10^{-9} \mathrm{~mm} / \mathrm{s}$ \\
\hline
\end{tabular}


The drift in chemistry (primarily Li) during the test is unlikely to have had a measurable effect on the SCC growth rates observed. Initially, the chemistry was quite stable (Figures 4-3 and 4-15), although in the longer term (Figures 4-4 and 4-16), the solution conductivity drifted upward, primarily from an increase in $\mathrm{Li}+$ associated with the clean-up of metal ions (mostly $\mathrm{Fe}+2$ ). By the end of the test, the Li content had increased from $1.1 \mathrm{ppm}$ to $2.5 \mathrm{ppm}$, while the $\mathrm{B}$ concentration was constant $(550 \mathrm{ppm}$ vs. $535 \mathrm{ppm})$. This produces an increase in the $\mathrm{pH}$ at $340^{\circ} \mathrm{C}$ from 7.60 to 7.95 (the equivalent change in $\mathrm{pH}$ at $300^{\circ} \mathrm{C}$ is from 6.93 to 7.29 ). This change of $0.35 \mathrm{pH}$ units translates to a decrease in corrosion potential of about $43 \mathrm{mV}$. The important thing to recognize about changes in potential that result from changes in $\mathrm{pH}$ is that they don't affect the relative location of the corrosion potential to metal - metal oxide phase transitions (esp. Ni/NiO), because they have the same $\mathrm{pH}$ dependency (Figure 4-25). Additionally, a recent test on Alloy 600 (Figure 4-26) showed no measurable change in crack growth rate at constant $\mathrm{K}$ for a similar change in $\mathrm{pH}$.

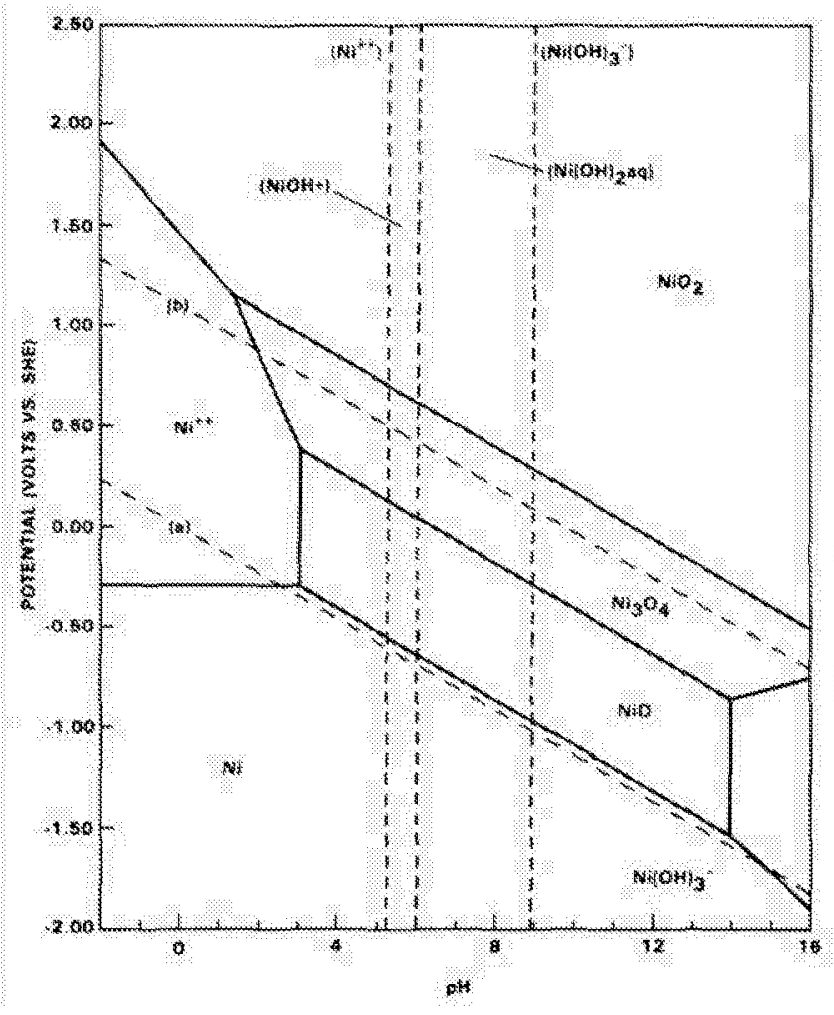

Figure 4-25

Pourbaix (pH - Potential) Diagram for the $\mathrm{Ni}_{2} \mathrm{H}_{2} \mathrm{O}$ system at $300^{\circ} \mathrm{C}$ showing that the $\mathrm{H}_{2} / \mathrm{H}_{2} \mathrm{O}$ Line (which Controls the Corrosion Potential) is Parallel to the Ni/NiO Boundary 


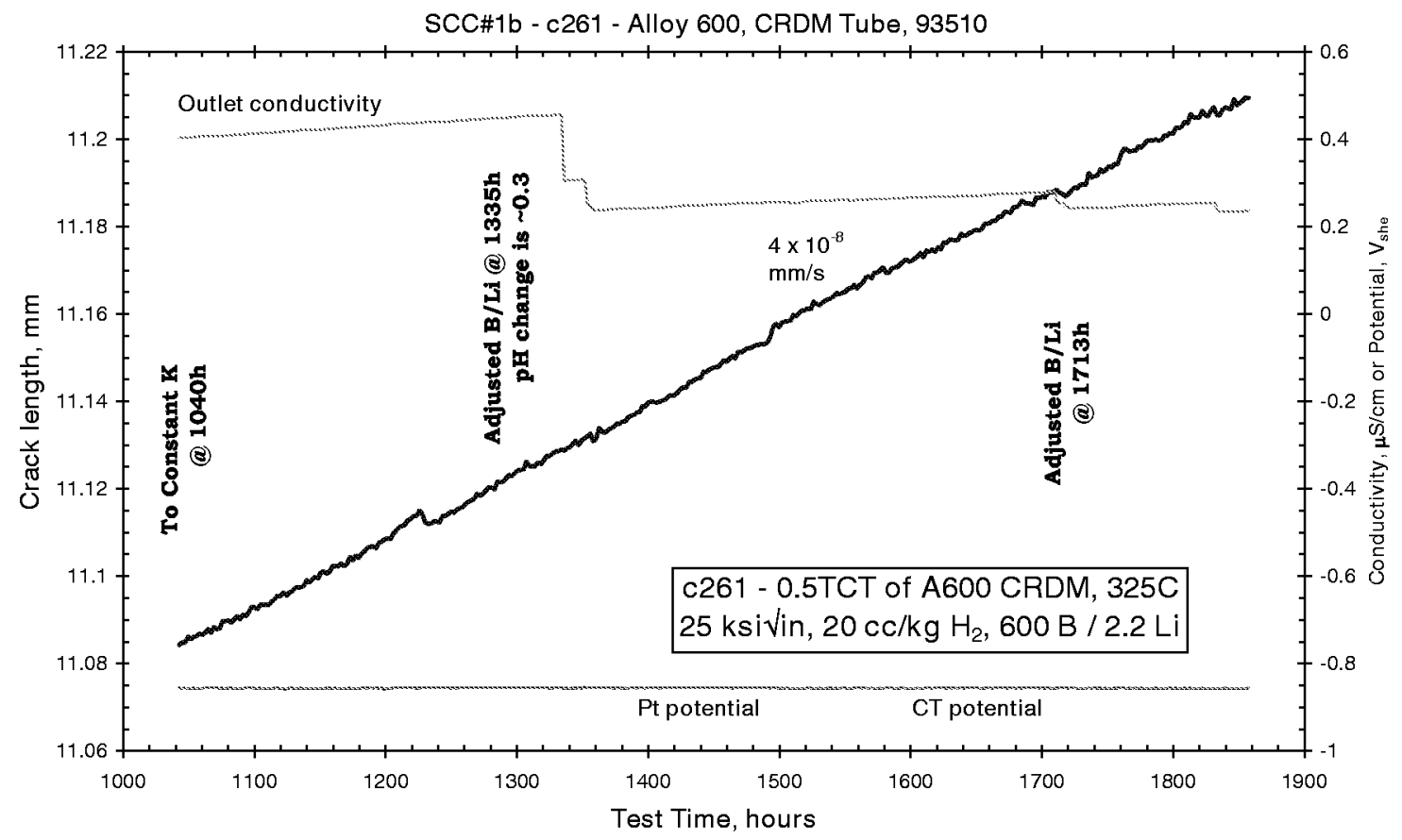

Figure 4-26

Crack Length vs. Time Response of Specimen c261 of Alloy 690, Heat 93510 (CRDM Housing) Tested in $325^{\circ} \mathrm{C}$ PWR Water with $20 \mathrm{cc} / \mathrm{kg} \mathrm{H} 2$ showing the Absence of an Effect on Crack Growth Rate of a 0.3 pH Unit Change in B/Li Chemistry

The possibility that changing resistivity vs. time for the alloy 690 specimens affected the measured crack growth rates is remote. Alloy 690 shows less resistivity shift than alloy 600, and the peak effect on annealed Ni alloys occurs between about 315 and $325^{\circ} \mathrm{C}$. When cold worked, the peak shifts downward by perhaps $15-25^{\circ} \mathrm{C}$. Finally, near the peak temperature, the effects are most prominent in the first 2000 hours, and the kinetics are faster at higher temperatures. This, in combination with cold work and the lesser effect in alloy 690, make it very unlikely that resistivity shifts affected the on-line dcpd measurements that were made.

While it was expected that the fracture surface in Alloy 690 for any crack growth at constant K (i.e., through SCC) would be predominantly intergranular, not transgranular, as actually observed, there are a number of pragmatic and theoretical factors to consider here. First, the growth rates are very low. Thus, the increments of growth obtained in the present tests - even after several thousand hours - were of the same order as, or smaller than, the grain size. This obviously gives a limited opportunity for intergranular growth at constant K (although some would still be expected, because along the crack front there will obviously be some areas wellaligned with an intersected grain boundary).

Second, it is clear that the relative preference of a stress corrosion (or corrosion fatigue) crack for the grain boundary path varies immensely with composition and microstructure. For example, in sensitized stainless steels in BWR water, a very highly intergranular cracking morphology persists to reasonably high frequency and $\Delta \mathrm{K}$ conditions. In annealed stainless steels in $\mathrm{BWR}$ water, this is not the case, and minor amounts of cycling can produced mixed mode or 
transgranular cracking. In materials without any significant microchemical gradient along the grain boundary, it is widely accepted that the crack preference for the grain boundary is related to the deformation and slip accommodation processes that can occur preferentially there.

However, if the nature of the matrix and grain boundary material is such that the grain boundary becomes of very subtle or no preference, then a shift to transgranular cracking should not be surprising (indeed, carbon and low alloy steels usually crack almost entirely in a transgranular mode in high temperature water). The same dynamic deformation, exposure of bare metal at slip offsets, corrosion and repassivation processes can still occur. Since grain boundaries are almost always the weak point in the microstructure, the observation of transgranular cracking, as is this preliminary testing work on cold-worked Alloy 690 , is thus consistent with a material that possesses inherently high resistance to SCC. 



\section{5 \\ CONCLUSIONS}

The goal of this limited program - to develop advanced techniques to evaluate the PWSCC resistance of Alloy 690 - was successfully achieved. As has been consistently shown for many other SCC-resistant materials, some inherent susceptibility to SCC was still observed to exist. Thus, while Alloy 690 lived up to its good reputation as an SCC-resistant material, stable, sustained SCC growth - albeit at very low rates - was observed on two cold-worked specimens during the entire 2400 hour test duration at constant $\mathrm{K}$ in simulated primary water at $340^{\circ} \mathrm{C}$.

The agreement between dc potential drop and the actual crack length determined from post-test fractography was excellent (11\% error for one specimen, $4 \%$ error for the other), giving confidence in the reliability of the technique to monitor even very low crack growth rates.

The final annealing temperature ( $\left.1800 \mathrm{vs.} 2000^{\circ} \mathrm{F}\right)$ of the Alloy 690 did not appear to affect the results in this preliminary work. However, the microstructure of the $1800^{\circ} \mathrm{F}$ material exhibited compositional and carbide banding, less uniformity in grain size, and a lower density of carbides in the grain boundary.

The crack morphology at truly constant load was primarily transgranular, although some evidence of intergranular primary and secondary cracking was observed. Since grain boundaries are almost always the weak point in the microstructure, the observation of transgranular cracking is consistent with a material that possesses inherently high resistance to SCC.

The highest sustained rate - for 1000 hours on specimen c 249 - was $8 \times 10^{9} \mathrm{~mm} / \mathrm{s}$, which corresponds to about $0.25 \mathrm{~mm} /$ year. Over the 2400 hour period at constant $\mathrm{K}$, the growth rates decreased by $30-50 \%$ in both specimens, although there was no sign of a tendency for crack arrest. 



\section{6 \\ REFERENCES}

1. P.L. Andresen, "Perspective and Direction of Stress Corrosion Cracking in Hot Water", Proc. Tenth Int. Symp. on Environmental Degradation of Materials in Nuclear Power Systems - Water Reactors, NACE, 2001.

2. P.L. Andresen, T.M. Angeliu and L.M. Young, "Immunity, Thresholds, and Other SCC Fiction", Proc. Staehle Symp. on Chemistry and Electrochemistry of Corrosion and SCC, TMS, Feb. 2001.

3. P.L. Andresen, L.M. Young, P.W. Emigh and R.M. Horn, "Stress Corrosion Crack Growth Rate Behavior of Ni Alloys 182 and 600 in High Temperature Water", Corrosion/02, Paper 02510, NACE, 2002.

4. P.L. Andresen, "Conceptual Similarities and Common Predictive Approaches for SCC in High Temperature Water Systems", Paper 96258, Corrosion/96, NACE, 1996.

5. F.P. Ford and P.L. Andresen, "Corrosion in Nuclear Systems: Environmentally Assisted Cracking in Light Water Reactors", in "Corrosion Mechanisms", Ed. P. Marcus and J. Ouder, Marcel Dekker, p.501-546, 1994.

6. P.L. Andresen and C.L. Briant, "Environmentally Assisted Cracking of Types 304L/316L/316NG Stainless Steel in $288^{\circ}$ C Water," Corrosion, Vol. 45, pp. 448-463, 1989.

7. P.L. Andresen, "Environmentally Assisted Growth Rate Response of Nonsensitized AISI 316 Grade Stainless Steels in High Temperature Water," Corrosion 44, 7, p. 450, 1988.

8. P.L. Andresen, "SCC Testing and Data Quality Considerations", Ninth Int Symp on Environmental Degradation of Materials in Nuclear Power Systems - Water Reactors, AIME, 1999. See also, P.L. Andresen, "Experimental Quality Guidelines for SCC Testing", GE CRD, January 30, 1998.

9. P.L. Andresen, K. Gott and J.L. Nelson, "Stress Corrosion Cracking of Sensitized Type 304 Stainless Steel in $288^{\circ} \mathrm{C}$ Water: A Five Laboratory Round Robin", Proc. Ninth Int. Symp. on Environmental Degradation of Materials in Nuclear Power Systems - Water Reactors, AIME, 1999.

10. L.W. Niedrach, "A New Membrane Type $\mathrm{pH}$ Sensor for Use in High Temperature High Pressure Water", J. Electrochem. Soc. 127, p. 2122, 1980.

11. T.M. Angeliu, P.L. Andresen, J.A. Sutliff and R.M. Horn, "Intergranular Stress Corrosion Cracking of Unsensitized Stainless Steels in BWR Environments", Proc. Ninth Int. Symp. on Environmental Degradation of Materials in Nuclear Power Systems - Water Reactors, AIME, 1999.

12. T.M. Angeliu, P.L. Andresen, E. Hall, J.A. Sutliff, S. Sitzman, M. Yamamoto, J. Kuniya, "Strain and Microstructure Characterization of Austenitic Stainless Steel Weld HAZs", Corrosion/2000 Paper \#00186, NACE, 2000. 
13. J.A. Sutliff, "An Investigation of Plastic Strain in Copper by Automated-EBSP”, Microscopy and Microanalysis, Vol 5. Supp. 21999 p. 236 (Proceedings: Microscopy \& Microanalysis '99).

14. D.S. Morton, S.A. Attanasio, J.S. Fish, and M.K. Schurman, "Influence of Dissolved Hydrogen on Nickel Alloy SCC in High Temperature Water", Corrosion/99, Paper 99447, NACE, 1999.

15. D.S. Morton, S.A. Attanasio, G.A. Young, P.L. Andresen, and T.M. Angeliu, "The Influence of Dissolved Hydrogen on Nickel Alloy SCC: A Window to Fundamental Insight", Paper 01117, Corrosion/01, NACE, 2001.

16. D.S. Morton, S.A. Attanasio and G.A. Young, "Primary Water SCC Understanding and Characterization Through Fundamental Testing in the Vicinity of the Ni/NiO Phase Transition", Proc. 10th Int. Symp. on Environmental Degradation of Materials in Nuclear Power Systems - Water Reactors, NACE, 2002.

17. P.L. Andresen, unpublished data on resistivity changes vs. time in Ni alloys, GE Global Research, Schenectady, NY, August 1994.

18. C.D. Thompson, D.M. Carey, and N.L. Perazzo, "Effects of Hydrogen on Electropotential Monitoring of Stress Corrosion Crack Growth", Eighth Int. Symp. on Environmental Degradation of Materials in Nuclear Power Systems - Water Reactors, ANS, p. 366, 1997.

19. P.L. Andresen, "Experimental Quality Guidelines for SCC Testing”, Guidelines Developed in Conjunction with the International Cooperative Group on Environmentally Assisted Cracking, John Hickling, Scientific Secretary, January 30, 1998.

20. P.L. Andresen, "Round Robin on Nickel Alloys $600 \& 182$ for Comparison and Optimization of SCC Growth Rate Data", Specification adopted by the International Cooperative Group on Environmentally Assisted Cracking, John Hickling, Scientific Secretary, January 15, 2003.

21. P.L. Andresen, L.M. Young, and P.W. Emigh, "SCC of Annealed and Cold Worked Titanium Grade 7 and Alloy 22 in $110^{\circ} \mathrm{C}$ Concentrated Salt Environments", Paper \#01130, Corrosion/01, NACE, 2001.

22. G.A. White, J. Hickling and L.K. Matthews, "Crack growth rates for evaluating PWSCC of thick-wall Alloy 600 material”, Proc. 11th Int. Symp. on Environmental Degradation of Materials in Nuclear Power Systems - Water Reactors, ANS, p.166-179, 2004. 

WARNING, This Docungent contains. information classified under U.S. Export. Control regulations as restricted from export outside the United States. You are under an obligation to ensure that you have a legal right to obtain acesess to this information and to ensure that you obtain an expoot. license prior to any re-export of this information. Special restrictions apply to access by anyone that is not a United States citizen or a Permanent United States resident: Iort turther intormation regarding your obligations, please, see the information contained below in the section titled "Export Control Restrictions?"

\section{Export Control Restrictions}

Access to and use of EPRI Intellectual Property is granted with the specific understanding and requirement that responsibility for ensuring full compliance with all applicable U.S. and foreign export laws and regulations is being undertaken by you and your company. This includes an obligation to ensure that any individual receiving access hereunder who is not a U.S. citizen or permanent U.S. resident is permitted access under applicable U.S. and foreign export laws and regulations. In the event you are uncertain whether you or your company may lawfully obtain access to this EPRI Intellectual Property, you acknowledge that it is your obligation to consult with your company's legal counsel to determine whether this access is lawful. Although EPRI may make available on a case by case basis an informal assessment of the applicable U.S. export classification for specific EPRI Intellectual Property, you and your company acknowledge that this assessment is solely for informational purposes and not for reliance purposes. You and your company acknowledge that it is still the obligation of you and your company to make your own assessment of the applicable U.S. export classification and ensure compliance accordingly. You and your company understand and acknowledge your obligations to make a prompt report to EPRI and the appropriate authorities regarding any access to or use of EPRI Intellectual Property hereunder that may be in violation of applicable U.S. or foreign export laws or regulations.

\section{About EPRI}

EPRI creates science and technology solutions for the global energy and energy services industry. U.S. electric utilities established the Electric Power Research Institute in 1973 as a nonprofit research consortium for the benefit of utility members, their customers, and society. Now known simply as EPRI, the company provides a wide range of innovative products and services to more than 1000 energyrelated organizations in 40 countries. EPRI's multidisciplinary team of scientists and engineers draws on a worldwide network of technical and business expertise to help solve today's toughest energy and environmental problems.

(C) 2004 Electric Power Research Institute (EPRI), Inc. All rights reserved. Electric Power Research Institute and EPRI are registered service marks of the Electric Power Research Institute, Inc. EPRI. ELECTRIFY THE WORLD is a service mark of the Electric Power Research Institute, Inc. 